\title{
Static and Dynamic Light Scattering
}

\author{
G. C. Berry \\ Department of Chemistry \\ Carnegie Mellon University \\ Pittsburgh, PA, USA \\ P. M. Cotts \\ Experimental Station \\ E. I. duPont \\ Wilmington, DE, USA
}

INTRODUCTION 1

SCATTERING RELATIONS 2

Scattered Intensity Measures $\quad 2$

Static Scattering Relations $\quad 2$

Dynamic Scattering Relations $\quad 6$

EXPERIMENTAL METHODS $\quad 8$

$\begin{array}{lr}\text { Light Scattering Instrumentation } & 8\end{array}$

$\begin{array}{lr}\text { Optical Alignment } & 9\end{array}$

Calibration $\quad 10$

Optical Factors $\quad 12$

Volume and refraction effects.

Optical Attenuation. $\quad 14$

Polarization Factor $\quad 14$

Calibration Standard $\quad 14$

Sample Preparation $\quad 14$

DATA TREATMENT 16

Static Scattering $\quad 16$

Dynamic Scattering $\quad 18$

EXAMPLES 21

Static Scattering and Size Exclusion Chromatography $\quad 21$

Intermolecular Association $\quad 23$

Scattering from Charged Species $\quad 24$

REFERENCES 26

$\begin{array}{lr}\text { APPENDIX } & 29\end{array}$

Table 1. Advantages/Disadvantages of Light Scattering $\quad 30$

Table 2 Light Scattering Average Mean-Square Radius of Gyration and 31 Hydrodynamic Radius 


\section{ABSTRACT}

Static and dynamic light scattering methods for use in the characterization of dilute solutions of polymers or suspensions of dispersed particles are presented. The theoretical foundations are summarized to give the expressions most often utilized, central issues in the calibration and use of light scattering photometers are considered, and several examples are discussed, including the use of light scattering as a detector in connection with size exclusion chromatograpy. 


\section{INTRODUCTION}

The use of light scattering methods to characterize polymers or colloidal particles in dilute solutions (dispersions) is discussed in the following. As many comprehensive discussions of the theoretical basis for the methods of interest are available [1-9], the limited space here is devoted to some of the more practical aspects of the several scattering methods to be discussed. Further, reference will usually be made to these sources, where the original studies are cited. In view of its purpose, this discussion is limited for the most part to the characterization methods that can be done with commercially available instrumentation, including equipment designed for stand alone scattering studies and instrumentation for use as a detector for a chromatographic analysis. It is well at the outset to recognize the advantages and limitations of the light scattering method, the principal of which are summarized in Table 1 . These will be mentioned below where appropriate.

Except where otherwise stipulated, the following is limited without further specific comment to an optically isotropic solute (no depolarized scattering) with a uniform composition (e.g., a solute with refractive index increment $\partial \mathrm{n} / \partial \mathrm{c}$ the same for all scatterers). It is assumed that the solutions are dilute, and amenable to treatments requiring extrapolation to infinite dilution. More complex relations may be required for optically anisotropic solute that result in depolarized scattering [6] (e.g., certain rodlike or helical chains), for compositionally heterogeneous solute [6; 10] (e.g., certain copolymers or very low molecular weight polymers), for polyelectrolytes dissolved in an electrolyte-free solvent [3; 11], and moderately concentrated solutions [12].

The following comprises four principal sections: (i) the presentation of the fundamental relations needed to interpret static and dynamic light scattering data from the stipulated systems, (ii) a discussion of experimental methods, (iii) procedures for data treatment, and (iv) a brief discussion of the application of scattering methods to the study of intermolecular association, the use of light scattering as a detector in size exclusion chromatography (SEC), and the scattering from charged species. 


\section{SCATTERING RELATIONS}

\section{Scattered Intensity Measures}

Static and dynamic scattering relations will be discussed in the next two sections. As a preliminary to that discussion, it is convenient to introduce the properties determined experimentally that appear in these relations. In general the scattering in the scattering plane, the plane containing the incident and scattered beams, will be determined as a function of the scattering angle $\vartheta$, or modulus $q=(4 \pi \mathrm{n} / \lambda) \sin (\vartheta / 2)$ of the scattering vector (the wavenumber), with $\mathrm{n}$ the refractive index of the solution and $\lambda$ the wave length of the incident light in vaccuo. Often, the incident light is plane polarized perpendicular to the scattering plane, but other arrangements may also be of interest, as discussed below. If digital methods are employed, the principal function of interest in either static or dynamic light scattering is the (unnormalized) photon count autocorrelation function $\mathrm{G}^{(2)}(\tau ; \mathrm{q})$ computed from the photon count statistics for a given $\mathrm{q}[4 ; 6-8 ; 13]$ :

$$
G^{(2)}(\tau ; q)=\langle\tilde{n}(t ; q) \tilde{n}(\tau+t ; q)\rangle_{t}
$$

where $\tilde{n}(t)$ is the number of photons detected over the time interval t to $t+\Delta t$, and the average is over the time of the data acquisition, which must exceed the longest correlation times in the photon count statistics, see below; the effect of the interval $\Delta t$ on the result is discussed in detail elsewhere [6]. In the limit with $\tau$ longer than all such correlation times, $G^{(2)}(\tau ; q)$ tends to an asymptotic limit $G^{(2)}(\infty ; q)$, with $\left[G^{(2)}(\infty ; q)\right]^{1 / 2}$ proportional to the time-averaged intensity $\mathrm{I}(\mathrm{q})$ of the scattered light. The Rayleigh ratio $\mathbf{R}(\mathrm{q})$ is given by $\mathrm{r}^{2} \mathrm{I}(\mathrm{q}) / \mathrm{VI}_{\mathrm{INC}}$, with $\mathrm{r}$ the distance between the scattering centers and the detector, $\mathrm{V}$ the scattering volume, and $\mathrm{I}_{\mathrm{INC}}$ the intensity of the incident light $[3 ; 4 ; 6]$. With analog detectors, the measured signal $A(q)$ is proportional to $I(q)$. Notation to indicate the dependence of $\mathrm{G}^{(2)}(\tau ; \mathrm{q})$ and $\mathbf{R}(\mathrm{q})$ on solute concentration $\mathrm{c}$ is suppressed here, for convenience but, for example, $\mathbf{R}(q)=\mathbf{R}(q, c), G^{(2)}(\tau ; q)=G^{(2)}(\tau ; q, c)$, etc., and this notation will be used below where needed for clarity. Relations presented below assume that the incident beam is vertically polarized and that the vertically polarized component of the scattered beam is isolated, unless otherwise specified.

\section{Static Scattering Relations}

As implied by the preceding, $\mathbf{R}(\mathrm{q})$ is of central importance for the interpretation of static (or elastic) scattering, carrying information on the intramolecular properties of the molecular weight $\mathrm{M}$ and root-mean-square radius of gyration $\mathrm{R}_{\mathrm{G}}$, as well as the intermolecular property of the second virial coefficient $\mathrm{A}_{2}$, and possibly higher order

virial coefficients. Actually, it is the excess value $\mathbf{R}_{\mathrm{xs}}(\mathrm{q}, \mathrm{c})=[\mathbf{R}(\mathrm{q}, \mathrm{c})]_{\mathrm{SOLN}}-[\mathbf{R}(\mathrm{q}, \mathrm{c})]_{\text {SOLVENT }}$ of 
the Rayleigh ratio for the solution less that for the solvent that is usually of interest. Consequently, unless needed for clarity, the subscript ' $x s^{\prime}$ will be suppressed, and $\mathbf{R}(q, c)$ will imply the excess quantity.

The behavior extrapolated to zero scattering angle may be expressed by either of the (equivalent) relations $[3 ; 6]$

$$
\begin{aligned}
\left(\frac{\mathrm{Kc}}{\mathbf{R}(0, \mathrm{c})}\right) & =\left(\frac{1}{\mathrm{M}_{\mathrm{LS}}}\right)\left\{1+2\left(\mathrm{~A}_{2}\right)_{\mathrm{LS}} \mathrm{M}_{\mathrm{LS}} \mathrm{c}+3\left(\mathrm{~A}_{3}\right)_{\mathrm{LS}} \mathrm{M}_{\mathrm{LS}} \mathrm{c}^{2}+\ldots\right\} \\
\left(\frac{\mathrm{Kc}}{\mathbf{R}(0, \mathrm{c})}\right)^{1 / 2} & =\left(\frac{1}{\mathrm{M}_{\mathrm{LS}}}\right)^{1 / 2}\left\{1+\left(\mathrm{A}_{2}\right)_{\mathrm{LS}} \mathrm{M}_{\mathrm{LS}} \mathrm{c}+\alpha_{3}\left(\left(\mathrm{~A}_{2}\right)_{\mathrm{LS}} \mathrm{M}_{\mathrm{LS}} \mathrm{c}\right)^{2}+\ldots\right\}
\end{aligned}
$$

where $\alpha_{3}=\left\{3\left(\mathrm{~A}_{3}\right)_{\mathrm{LS}} \mathrm{M}_{\mathrm{LS}} /\left(\left(\mathrm{A}_{2}\right)_{\mathrm{LS}} \mathrm{M}_{\mathrm{LS}}\right)^{2}-1\right\} / 2, \mathrm{~K}=\left(4 \pi^{2} / \mathrm{N}_{\mathrm{A}} \lambda^{4}\right)\left\{\mathrm{n}(\partial \mathrm{n} / \partial \mathrm{c})_{\mu}\right\}^{2}$ for vertically polarized incident and scattered light, with $(\partial \mathrm{n} / \partial \mathrm{c})_{\mu}$ the refractive index increment at osmotic equilibrium of solvent components (see further below), $\mathrm{M}_{\mathrm{LS}}$ and $\left(\mathrm{A}_{2}\right)_{\mathrm{LS}}$ are the light scattering averaged molecular weight and second virial coefficient, respectively, etc. The second form is useful for systems with large $A_{2}$ ("good solvents") as $\alpha_{3}$ tends to be small, making the extrapolation more nearly linear to larger $\left(\mathrm{A}_{2}\right)_{\mathrm{LS}} \mathrm{M}_{\mathrm{LS}} \mathrm{C}$ than with the first form.

For the optically isotropic, compositionally homogeneous solute stipulated above, $\mathrm{M}_{\mathrm{LS}}$ is given by $[3 ; 6]$

$$
\mathrm{M}_{\mathrm{LS}}=\mathrm{M}_{\mathrm{w}}=\sum \mathrm{w}_{\mu} \mathrm{M}_{\mu}
$$

for a solute with a distribution of molecular weight, where $w_{\mu}$ is the weight fraction of component $\mu$ with molecular weight $\mathrm{M}_{\mu}$. More complicated expressions may be necessary for copolymers and for a solute in a mixed solvent $[3 ; 10]$. It should be noted that these relations apply to polymeric or colloidal solute, and that similar relations also obtain for the scattering of $x$-rays and neutrons (with revision of the definition for $\mathrm{K}$ in Eq. 2). An expression to account for the effects of heterogeneity on $\left(\mathrm{A}_{2}\right)_{\mathrm{LS}}$ may also be used where necessary $[3 ; 6]$.

Similarly, certain relations provide a universal description of the dependence of the scattering extrapolated to infinite dilution on the scattering angle $[3 ; 6]$. Thus, the scattering at infinite dilution is given by

$$
\left(\frac{\mathrm{Kc}}{\mathbf{R}(\mathrm{q}, \mathrm{c})}\right)^{\mathrm{O}}=\frac{1}{\mathrm{M}_{\mathrm{w}} \mathrm{P}_{\mathrm{LS}}(\mathrm{q})}=\left(\sum \mathrm{w}_{\mu} \mathrm{M}_{\mu} \mathrm{P}_{\mu}(\mathrm{q})\right)^{-1}
$$




$$
\mathrm{P}_{\mathrm{LS}}(\mathrm{q})^{-1}=1+\left(\mathrm{R}_{\mathrm{G}}^{2}\right)_{\mathrm{LS}} \mathrm{q}^{2} / 3+\ldots
$$

where the light scattering averaged mean square radius of gyration $\left(R_{G}^{2}\right)_{L S}$ is defined in Table 2, and the super zero (o) denotes a quantity extrapolated to infinite dilution. The particle scattering function $\mathrm{P}(\mathrm{q})$ is known for a variety of solute forms (e.g., coils, rods, spheres, etc.) $[1-3 ; 6 ; 14 ; 15]$, but the second relation provides a generally valid expansion of $\mathrm{P}_{\mathrm{LS}}(\mathrm{q})$ for $\left(\mathrm{R}_{\mathrm{G}}^{2}\right)_{\mathrm{LS}} \mathrm{q}^{2}<1$, independent of the solute shape (within the stipulations given above). Expressions for $\left(\mathrm{R}_{\mathrm{G}}^{2}\right)_{\mathrm{LS}}$ for a solute with a uniform composition, but a distribution of molecular weight are given in Table 2. Relations are included for the special case with $\mathrm{R}_{\mathrm{G}}^{2} / \mathrm{M}^{\varepsilon}$ independent of $\mathrm{M}$, with $\varepsilon$ specific to the solute shape. As above, these relations apply to polymeric or colloidal solute, and similar relations also obtain for the scattering of $\mathrm{x}$-rays and neutrons.

In certain cases, the nature of $\mathrm{P}_{\mathrm{LS}}(\mathrm{q})$ may motivate a special approximation at small $\left(R_{\mathrm{G}}^{2}\right)_{\mathrm{LS}} \mathrm{q}^{2}$. For example, for a linear, monodisperse random-flight linear chain model, for which $\left(\mathrm{R}_{\mathrm{G}}^{2} / \mathrm{M}\right)$ is independent of $\mathrm{M}$, the relation $[3 ; 6]$

$$
\left(\left(\frac{\mathrm{Kc}}{\mathbf{R}(\mathrm{q}, \mathrm{c})}\right)^{\mathrm{o}}\right)^{1 / 2}=\left(\frac{1}{\mathrm{M}}\right)^{1 / 2}\left\{1+\mathrm{R}_{\mathrm{G}}^{2} \mathrm{q}^{2} / 6+\ldots\right\}
$$

facilitates extrapolation to obtain $\mathrm{M}$ and $\mathrm{R}_{\mathrm{G}}^{2}$ [3], whereas for the same model with a most-probable distribution of molecular weights [3; 6; 16;17],

$$
\left(\frac{\mathrm{Kc}}{\mathbf{R}(\mathrm{q}, \mathrm{c})}\right)^{\mathbf{O}}=\frac{1}{\mathrm{M}_{\mathrm{w}}}\left\{1+\left(\mathrm{R}_{\mathrm{G}}^{2} / \mathrm{M}\right) \mathrm{M}_{\mathrm{z}} \mathrm{q}^{2} / 3\right\}
$$

and the use of the square-root plot would not be desirable. Clearly, approximations such as these must be used with care.

In some cases, the detailed angular dependence can provide additional information on the shape or the size distribution of the solute. Examples of $\mathrm{P}(\mathrm{q})$ are available for a variety of solute shapes, and the appropriate averaging for light scattering to compute $\mathrm{P}_{\mathrm{LS}}(\mathrm{q})$ is well established $[3 ; 6 ; 14-16]$. A few of the more frequently encountered $P(q)$ are given in Figure 1. The insert shows the deviation of $P(q)$ for rods, disk and spheres form $\mathrm{P}(\mathrm{q})$ for the random-flight linear chain. Expressions for these are included in the Appendix; the functions may be readily calculated using a desk-top computer. The random-flight chain model is frequently appropriate for analysis of $\mathrm{P}(\mathrm{q})$ 
for synthetic polymers, including a variety of branched chain polymers. A useful approximation to $\mathrm{P}(\mathrm{q})$ for comb-shaped branched chain polymers is given by $\mathrm{P}(\mathrm{q})$ for linear chains, using $R_{G}^{2}$ for the branched chain in the calculation. Nevertheless, as demonstrated by the examples of this approximation given in Figure 2, the approximation will usually be limited to $R_{G}^{2} q^{2}$ less than about unity [6]. It should be realized that molecular weight dispersion will alter the shape of $\mathrm{P}(\mathrm{q})$ from the appearance in Figure 1, see reference [6]. An example of this for the random-flight linear chain is given in the Appendix.

An analysis of $\mathrm{P}_{\mathrm{LS}}(\mathrm{q})$ is sometimes used to estimate the size distribution of an optically isotropic spherical solute polydisperse in size, but homogenous in composition, by comparison of the observed $\{\mathbf{R}(\mathrm{q}, \mathrm{c}) / \mathbf{R}(0, \mathrm{c})\}^{\mathrm{O}}$ with $\mathrm{P}_{\mathrm{LS}}(\mathrm{q})$ calculated for this model (frequently, $\mathbf{R}(\mathrm{q}, \mathrm{c}) / \mathbf{R}(0, \mathrm{c})$ at concentration $\mathrm{c}$ is used instead of the behavior exptrapolated to infinite dilution). For example, for the random-flight model for linear or branched macromolecules polydisperse in chain length, the behavior of $\mathrm{P}_{\mathrm{LS}}(\mathrm{q})$ at large $\left(\mathrm{R}_{\mathrm{G}}^{2}\right)_{\mathrm{LS}} \mathrm{q}^{2}$ gives [3; 6]:

$$
\lim _{\left(\mathrm{R}_{\mathrm{G}}^{2}\right)_{L S} \mathrm{q}^{2} \gg>1}\left(\frac{\mathrm{Kc}}{\mathbf{R}(\mathrm{q}, \mathrm{c})}\right)^{\mathrm{O}}=\left(1 / 2 \mathrm{M}_{\mathrm{n}}\right)\left\{2 \mathrm{C}+\left(\mathrm{R}_{\mathrm{G}}^{2} / \mathrm{M}\right) \mathrm{M}_{\mathrm{n}} \mathrm{q}^{2}+\mathrm{O}\left(\mathrm{q}^{-1}\right)\right\}
$$

where $C$ is $1 / 2$ for linear chains and a function of the branching for branched chains. When applicable, this relation provides a means in principle to evaluate $M_{w} / M_{n}$ from light scattering data. Similar relations are available for solutes of other shapes $[3 ; 6]$. In practice, $\left(R_{\mathrm{G}}^{2}\right)_{\mathrm{LS}} \mathrm{q}^{2}$ is usually not large enough to make this relation valid in the experimental angular range with light scattering, but it may be useful in the analysis of the scattering of neutrons or x-rays, which tend to involve larger q. It must be recognized, however, that the random-flight model will fail for very large $q$, reflecting the short-range structure in the chain neglected in that model $[3 ; 6]$.

The preceding has not addressed the question of the behavior when terms in both $c$ and $q$ must be considered. One form for this behavior, discussed below in the section on data treatment, is given by $[3 ; 6 ; 12 ; 14]$

$$
\left(\frac{\mathrm{Kc}}{\mathbf{R}(\mathrm{q}, \mathrm{c})}\right)=\frac{1}{\mathrm{M}_{\mathrm{w}}}\left\{\mathrm{P}_{\mathrm{LS}}^{-1}(\mathrm{q})+2 \mathrm{Q}_{\mathrm{LS}}(\mathrm{q})\left(\mathrm{A}_{2}\right)_{\mathrm{LS}} \mathrm{M}_{\mathrm{w}} \mathrm{c}+\ldots\right\}
$$

where $\mathrm{Q}_{\mathrm{LS}}(0)=1$. For flexible chains, $\mathrm{Q}_{\mathrm{LS}}(\mathrm{q}) \approx 1$, but $\mathrm{Q}_{\mathrm{LS}}(\mathrm{q})$ may deviate significantly from unity for scatterers with other shapes [12;18]. For example, for spheres of uniform size 
interacting through a hard-core potential, $\mathrm{Q}_{\mathrm{LS}}(\mathrm{q})=\mathrm{P}(\sqrt{ } 2 \mathrm{q})^{1 / 2} / \mathrm{P}(\mathrm{q})$. This relation will be discussed further in the section on data treatment.

\section{Dynamic Scattering Relations}

The photon-count autocorrelation function $\mathrm{G}^{(2)}(\tau ; \mathrm{q})$ determined in dynamic scattering is normalized by $\mathrm{G}^{(2)}(\infty ; \mathrm{q})$ to give $\mathrm{g}^{(2)}(\tau ; \mathrm{q})$, for which (for most solutes) [4; 6-8; 13]

$$
\mathrm{g}^{(2)}(\tau ; \mathrm{q}, \mathrm{c})=1+\mathrm{f}_{\mathrm{C}}\left\{\mathrm{g}^{(1)}(\tau ; \mathrm{q}, \mathrm{c})\right\}^{2}
$$

Here, $f_{C}=g^{(2)}(0 ; q)-1$ is expected to be independent of $q$ and $c$, see below. Further, for an optically isotropic solute, it is usually possible to represent $\mathrm{g}^{(1)}(\tau ; \mathrm{q}, \mathrm{c})$ by the expression $[4-8 ; 13]$

$$
g^{(1)}(\tau ; q, c)=\sum r_{\mu}(q, c) \exp \left[-\tau \gamma_{\mu}(q, c)\right]
$$

where $r_{\mu}(q, c)$ is the weight factor for the component with relaxation rate $\gamma_{\mu}(q, c) ; r_{\mu}(q, c)$ reduces to $\mathrm{w}_{\mu} \mathrm{M}_{\mu} / \mathrm{M}_{\mathrm{w}}$ in the limit of infinite dilution and zero scattering angle. More complex expressions may be required for very high molecular weight polymer chains, asymmetric particles, optically anisotropic solute or certain other systems $[4 ; 6]$.

A cumulant expression is often used to describe the behavior for small $\tau[4 ; 6-8]$ :

$$
\begin{aligned}
\ln \left[g^{(2)}(\tau ; \mathrm{q}, \mathrm{c})-1\right]^{1 / 2} & =\ln \left(\mathrm{f}_{\mathrm{C}}\right)^{1 / 2}-\mathrm{K}^{(1)}(\mathrm{q}, \mathrm{c}) \tau+\frac{1}{2 !} \mathrm{K}^{(2)}(\mathrm{q}, \mathrm{c}) \tau^{2}+\ldots \\
\mathrm{K}^{(1)}(\mathrm{q}, \mathrm{c}) & =-\frac{1}{2} \lim _{\tau=0} \frac{\partial \ln \left[\mathrm{g}^{(2)}(\tau ; \mathrm{q}, \mathrm{c})-1\right]}{\partial \tau}=\sum_{\mathrm{r}_{\mu}(\mathrm{q}, \mathrm{c}) \gamma_{\mu}(\mathrm{q}, \mathrm{c})}
\end{aligned}
$$

where $K^{(1)}(q, c)$ is the first cumulant, etc. For polarized scattering from optically isotropic solute, the first cumulant is used to compute the mutual diffusion coefficient $\mathrm{D}_{\mathrm{M}}(\mathrm{c})$ in the limit of small q:

$$
\lim _{q=0} K^{(1)}(q, c)=D_{M}(c) q^{2}
$$

It is useful to express $\mathrm{D}_{\mathrm{M}}(\mathrm{c})$ in terms of a diffusion scaling length $\mathrm{a}_{\mathrm{LS}}(\mathrm{c})$ to remove the effects of the viscosity for comparison of data in different solvents and at different 
temperatures:

$$
a_{L S}(c)=\frac{k T}{6 \pi \eta_{S} D_{M}(c)}
$$

Then, in the limit of infinite dilution, $\mathrm{a}_{\mathrm{LS}}(\mathrm{c})$ extrapolates to the light scattering averaged hydrodynamic radius $\left(\mathrm{R}_{\mathrm{H}}\right)_{\mathrm{LS}}$. Here, by definition, $\mathrm{R}_{\mathrm{H}}=\mathrm{kT} / 6 \pi \eta_{\mathrm{S}} \mathrm{D}_{\mathrm{T}}$, with $\mathrm{D}_{\mathrm{T}}$ the translational diffusion constant. Examples of $\left(R_{H}\right)_{L S}$ for several solutes heterodisperse in molecular weight are given in Table 2. It should be noted that the heterodispersity has very different effects on $\left(R_{H}\right)_{L S}$ and $\left(R_{G}^{2}\right)_{L S}$, such that in general these do not scale with the same average molecular weights.

The concentration dependence of $\mathrm{a}_{\mathrm{LS}}(\mathrm{c})$ (or $\mathrm{D}_{\mathrm{M}}(\mathrm{c})$ ) is normally less than that of $\mathrm{Kc} / \mathbf{R}(\mathrm{q}, \mathrm{c})$. For example,

$$
\mathrm{a}_{\mathrm{LS}}(\mathrm{c})=\left(\mathrm{R}_{\mathrm{H}}\right)_{\mathrm{LS}}\left\{1-\mathrm{k}_{\mathrm{D}}[\eta] \mathrm{c}+\ldots\right\}
$$

with $\mathrm{k}_{\mathrm{D}}=\left(2-\mathrm{k}_{2}\right)\left(\mathrm{A}_{2} \mathrm{M} /[\eta]\right)-\mathrm{k}_{1}$, where [ $\left.\eta\right]$ is the intrinsic viscosity, and both $\mathrm{k}_{1}$ and $\mathrm{k}_{2}$ have been estimated for various solute geometries $[6 ; 9 ; 12 ; 19]$. It should be noted that $\mathrm{k}_{\mathrm{D}}$ may be negative, even if $\mathrm{A}_{2}>0$.

In some cases it is useful to compute the inverse Laplace transform of $g^{(1)}(\tau ; q, c)$ to obtain additional information on the distribution of components comprising the solute. Algorithms to accomplish this are available, but should be used with caution since the problem is formally ill-posed, and inaccuracies may accrue even when constraints are imposed to stabilize the inversion $[7 ; 8 ; 13 ; 20 ; 21]$. Care must be exercised to respect the limitations on the minimum and maximum values of $\tau$ characterizing the experimental data, as well as the precision of the data under analysis. This method is discussed further in the following. 


\section{EXPERIMENTAL METHODS}

\section{Light Scattering Instrumentation}

Several components comprise light scattering photometers, including:

(1) the incident light source and its associated optics;

(2) the light scattering cell;

(3) the detector and its associated optics;

(4) the electronic components associated with the detector.

In addition, the experiment could require specialized apparatus in special cases, e.g., electrophoretic scattering requires the imposition of an electric field on the sample $[4 ; 6]$.

Most light scattering photometers make use of continuous gas lasers as light sources, ranging from a few milliwatts to a hundred milliwatts or so in output power. These are suitable for either static or dynamic scattering, with the latter benefiting from somewhat higher power levels. In many cases, for dynamic scattering the beam from the laser is used directly, or with some simple focusing into the scattering volume using a long focal length lens. Conversely, for reasons discussed in the next section, it is desirable to expand the beam in static scattering, though that is not always done in commercially available equipment. In either case, the polarization state of the light source must be specified. Usually this is a plane-polarized state in the direction vertical to the scattering plane (the plane containing the incident and scattered rays), see below. Neutral density filters are sometimes used to reduce the intensity of the beam in the scattering cell, but this is not generally advisable.

The detector optics are designed to control the angular acceptance of the scattered light, and the horizontal and vertical dimensions of the scattering volume--the depth of the scattering volume is controlled by the width of the incident beam. One of a few optical designs is usually employed in the detector optics [3; 8]. In dynamic scattering, the coherence area $A_{C}$ is controlled by a pin-hole place before the detector (e.g., in the focal plane of a lens interposed between the scattering cell and the detector, which is a multi-stage photomultiplier selected for appropriate wave-length response and electronic stability. The coherence factor $f_{C}$ (see Eq. 9) increases with decreasing $A_{C}$ (decreasing pin-hole diameter), but the photon count rate decreases with decreasing $\mathrm{A}_{\mathrm{C}^{\prime}}$ requiring a compromise for effective signal-to-noise ratio in measurements.

Adjustments to give $f_{C}$ in the range 0.3 to 0.6 are common in most cases. The angular resolution need not be so closely defined in static scattering, but the angular resolution and scattering volume must be known in one way or another at each scattering volume to permit assessment of $\mathbf{R}(\mathrm{q})$. In some designs this is facilitated by insuring that the scattering volume has a vertical dimension smaller than that of the incident beam [3], but other procedures may be adopted, as discussed below. It is usually advisable to place 
a band-pass filter with a high transmission for the scattered light before the detector to minimize the effects of any fluorescence from the sample or stray light from sources other than the incident beam. Similarly, a band-reject filter may be used to assess the presence of fluorescence. It is also advisable to place a polarizing filter of some kind before the detector, and it is essential to do this if the anisotropic scattering is to be studied. Unfortunately, not all commercially available instruments provide the option to place filters in the scattered beam.

\section{Optical Alignment}

In some cases, with commercially available light scattering photometers, the user has limited access to the optical alignment of the instrument. Nevertheless, a few central aspects of the optical alignment of a light scattering instrument will be mentioned here. Foremost among these is the polarization state of the incident and scattered beams. In many cases, a continuous laser will provide the incident light, often from a laser with Brewster windows to produce a plane polarized beam. The plane of polarization may then be rotated by rotation of a half-wave plate placed in the incident beam, providing a convenient tool for optical alignment. In the absence of a half-wave plate, the polarization plane may be rotated using a Polaroid ${ }^{\mathrm{TM}}$ polarization filter. In the alignment process described below, it is convenient to make use of a solution of an (essentially) optically isotropic polymer, such as a relatively low molecular weight polystyrene dissolved in a solvent that is itself nearly optically isotropic (e.g., carbon tetrachloride). With the polarization plane of the incident light adjusted to be close to the scattering plane ("horizontal polarization"), the scattering from the solution should be at a minimum at 90 degree scattering angle, and symmetric about that angle if the molecular weight of the polymer is small enough that $\left(R_{G}^{2}\right)_{L S} q^{2}$ $<1$ for all scattering angles. Measurement of a few scattering angles around 90 degrees will assess this, and permit any necessary adjustments in the angle scale. Usually, it will be desirable to have the polarization perpendicular to the scattering plane (the plane containing the incident and scattered beams). This may be conveniently verified by again monitoring the scattering from a suitable polymer solution at 90 degree scattering angle, with rotation of the plane of polarization about an angle close to the scattering plane, to determine the orientation for minimum signal. Rotation of the plane of polarization by 90 degrees from this orientation will then give vertically polarized light. If possible, it will usually be desirable to have a polarization analyzer of some kind in the scattered beam to allow selection of the polarization state of the detected scattered light. The alignment of this is conveniently accomplished by monitoring the scattering from the solution with incident light polarization perpendicular to the scattering plane ('vertically polarized'), as the preferred direction of the analyzer is aligned in the scattering plane to determine the position for minimum signal, corresponding to polarization orthogonal to that of the incident light 
('horizontal polarization'). Rotation of the analyzer to change the preferred state by 90 degrees will then select the polarization state parallel to that of the incident light.

\section{Calibration}

Although the optical arrangement is important in dynamic light scattering, as in the control of the coherence factor $\mathrm{f}_{\mathrm{C}}$, calibration factors are not needed in the analysis of $\mathrm{G}^{(2)}(\tau ; \mathrm{q})$ to determine the parameters of interest. By contrast, several factors are necessary in converting the response $\mathrm{D}(\mathrm{q})$ from the detector to useful parameters in the analysis of static light scattering, including [3]:

(1) the dependence of the scattering volume on angle and solvent;

(2) the effects of attenuation of the incident or scattered rays;

(3) the polarization state of the incident and scattered rays;

(4) the relation of the detected signal to $\mathbf{R}(q)$.

Thus, for example, $\mathrm{D}(\mathrm{q})=\mathrm{A}(\mathrm{q})$ for an analog detector, and $\mathrm{D}(\mathrm{q})$ is equal to the average count rate $\langle\tilde{\mathrm{n}}(\mathrm{q})\rangle$ with digital methods. Note, that in this section, and this section only, the notation $\mathbf{R}(\mathrm{q})$ refers to the actual Rayleigh ratio, and not to the excess Rayleigh ratio $\mathbf{R}_{\mathrm{xs}}(\mathrm{q})$ as in the preceding. Discussion of these effects will introduce several factors, summarized here for convenience (with $\vartheta$ the scattering angle, $\mathrm{n}$ the solution refractive index, $\mu$ an extinction coefficient, and $\lambda$ the wavelength of the scattered radiation in vaccuo):

$\mathrm{V}(\vartheta, \mathrm{n}) \quad$ The scattering volume at $\vartheta$ for a solution with refractive index $\mathrm{n}$

$\tilde{\mathrm{V}}_{90} \quad$ The (hypothetical) scattering volume in air for $\vartheta$ of 90 degrees

$\mathrm{f}_{\mathrm{V}}(\vartheta) \quad$ A factor to account for the dependence of $\tilde{\mathrm{V}}_{90} / \mathrm{V}(\vartheta, \mathrm{n})$ on $\vartheta$

$\mathrm{f}_{\mathrm{R}}(\mathrm{n}) \quad$ A factor to account for the dependence of $\widetilde{V}_{90} / \mathrm{V}(\vartheta, \mathrm{n})$ on $n$

$\mathrm{f}_{\mathrm{EXT}}(\vartheta, \mu) \quad$ A factor to account for attenuation in the solution (extinction $\mu$ )

$\mathrm{f}_{\mathrm{P}}(\vartheta) \quad$ A factor to account for the polarization of the incident beam

$\mathrm{f}_{\mathrm{CAL}}(\vartheta, \lambda) \quad$ A factor relating the corrected observed response to $\mathbf{R}(\mathrm{q})$

A number of these depending only on optical considerations are conveniently grouped together in a single parameter:

$$
\mathrm{k}(\mu, \mathrm{n}, \vartheta)=\mathrm{f}_{\mathrm{P}}(\vartheta) \mathrm{f}_{\mathrm{EXT}}(\mu, \vartheta) \tilde{V}_{90} / \mathrm{V}(\vartheta, \mathrm{n}) \approx \mathrm{f}_{\mathrm{P}}(\vartheta) \mathrm{f}_{\mathrm{EXT}}(\vartheta, \mu) \mathrm{f}_{\mathrm{V}}(\vartheta) \mathrm{f}_{\mathrm{R}}(\mathrm{n})
$$

With the factor $1 / \widetilde{\mathrm{V}}_{90}$ is subsumed into the definition for $\mathrm{f}_{\mathrm{CAL}}(\vartheta, \lambda), \mathbf{R}(\mathrm{q})$ may be expressed in terms of the normalized instrument response $\mathrm{D}(\mathrm{q}) / \mathrm{D}_{\mathrm{INC}}$ as

$$
\mathbf{R}(\mathrm{q})=\mathrm{k}(\mu, \mathrm{n}, \vartheta) \mathrm{f}_{\mathrm{CAL}}(\vartheta, \lambda) \mathrm{D}(\mathrm{q}) / \mathrm{D}_{\mathrm{INC}}
$$


where $\mathrm{D}_{\text {INC }}$ is a measure of the incident beam intensity (or a known fraction thereof). The parameter $\mathrm{D}_{\mathrm{INC}}$ may be determined directly by a measurement on the scattering beam using a special photodetector for that purpose, or may be taken as the scattering from some 'working standard', measured at intervals between the determination of $D(q)$, using the same detector for both. In the former case, the ratio $D(q) / D_{\text {INC }}$ may be formed in the electronics for each scattering angle. The various factors involved in $\mathrm{k}(\mu, n, \vartheta)$ are elaborated in the following section. The remaining parameter, $\mathrm{f}_{\mathrm{CAL}}(\vartheta, \lambda)$, is considered separately here.

Although $\mathrm{f}_{\mathrm{CAL}}(\vartheta, \lambda)$ may be computed absolutely in principle [3], that is rarely practical, and instead the response $\mathrm{D}(\mathrm{q}) / \mathrm{D}_{\text {INC }}$ from a "standard" with known $\mathbf{R}(\mathrm{q})$ is used to determine the $\mathrm{f}_{\mathrm{CAL}}(\vartheta, \lambda)$ for some particular angle $\vartheta^{*}$ (or, equivalently, $\mathrm{q}^{*}$ ), usually either 0 or 90 degree scattering angle. Thus, for the standard,

$$
\begin{aligned}
\mathrm{f}_{\mathrm{CAL}}(\vartheta, \lambda) & =\frac{1}{\mathrm{k}_{\mathrm{STD}}(\mu, \mathrm{n}, \vartheta)} \frac{[\mathbf{R}(\mathrm{q})]_{\mathrm{STD}}}{[\mathrm{D}(\mathrm{q})]_{\mathrm{STD}} / \mathrm{D}_{\mathrm{INC}}} \\
\mathrm{f}_{\mathrm{CAL}}\left(\vartheta^{*}, \lambda\right) & =\frac{1}{\mathrm{k}_{\mathrm{STD}}\left(\mu, \mathrm{n}, \vartheta^{*}\right)} \frac{\left[\mathbf{R}\left(\mathrm{q}^{*}\right)\right]_{\mathrm{STD}}}{\left[\mathrm{D}\left(\mathrm{q}^{*}\right)\right]_{\mathrm{STD}} / \mathrm{D}_{\mathrm{INC}}}
\end{aligned}
$$

Then, the relation between $\mathbf{R}(\mathrm{q})$ and $\mathrm{D}(\mathrm{q}) / \mathrm{D}_{\mathrm{INC}}$ may be expressed as

$$
\begin{aligned}
& \mathbf{R}(\mathrm{q})=\left[\mathbf{R}\left(\mathrm{q}^{*}\right)\right]_{\mathrm{STD}} \frac{\mathrm{f}_{\mathrm{CAL}}(\vartheta, \lambda)}{\mathrm{f}_{\mathrm{CAL}}\left(\vartheta^{*}, \lambda\right)} \frac{\mathrm{k}(\mu, \mathrm{n}, \vartheta)}{\mathrm{k}_{\mathrm{STD}}\left(\mu, \mathrm{n}, \vartheta^{*}\right)} \frac{\mathrm{D}(\mathrm{q}) / \mathrm{D}_{\mathrm{INC}}}{\left[\mathrm{D}\left(\mathrm{q}^{*}\right) / \mathrm{D}_{\mathrm{INC}}\right]_{\mathrm{STD}}} \\
& \mathbf{R}(\mathrm{q})=\hat{\mathrm{k}}_{\mathrm{STD}} \frac{\mathrm{f}_{\mathrm{CAL}}(\vartheta, \lambda)}{\mathrm{f}_{\mathrm{CAL}}\left(\vartheta^{*}, \lambda\right)} \frac{\mathrm{k}(\mu, \mathrm{n}, \vartheta)}{\mathrm{k}_{\mathrm{STD}}\left(\mu, \mathrm{n}, \vartheta^{*}\right)} \mathrm{D}(\mathrm{q}) / \mathrm{D}_{\mathrm{INC}}
\end{aligned}
$$

where the "calibration constant" $\hat{\mathrm{S}}_{\mathrm{STD}}$ is equal to $\left[\mathbf{R}\left(\mathrm{q}^{*}\right)\right]_{\mathrm{STD}} /\left[\mathrm{D}\left(\mathrm{q}^{*}\right) / \mathrm{D}_{\mathrm{INC}}\right]_{\mathrm{TD}}$. In some cases, the factor $1 / \mathrm{k}_{\text {STD }}\left(\mu, \mathrm{n}, \vartheta^{*}\right)$ is included in the calibration constant, but it is left explicit in this notation for convenience in the discussion to follow.

Two general arrangements to make use of these relations may be found in practice: (i) the use of a single detector mounted on a goniometer for use over a range of scattering angles, and (ii) the use of a separate detector for each angle. In the first case, $\mathrm{f}_{\mathrm{CAL}}(\vartheta, \lambda) / \mathrm{f}_{\mathrm{CAL}}\left(\vartheta^{*}, \lambda\right)$ is unity, but in the second case, the possible variation of $\mathrm{f}_{\mathrm{CAL}}(\vartheta, \lambda)$ with $\vartheta$ must be explicitly evaluated and included. This may be accomplished, for example, by measurement of $D(q) / D_{\text {INC }}$ for a fluid with known $\mathbf{R}(q)$. Since the same 
fluid could be used to evaluate $\mathrm{f}_{\mathrm{CAL}}(\vartheta, \lambda) / \mathrm{f}_{\mathrm{CAL}}\left(\vartheta^{*}, \lambda\right)$ and $\mathrm{f}_{\mathrm{V}}(\vartheta) /\left[\mathrm{f}_{\mathrm{V}}\left(\vartheta^{*}\right)\right]_{\mathrm{STD}}$, further discussion of this factor is taken up below, along with the evaluation of $\mathrm{f}_{\mathrm{V}}(\vartheta) /\left[\mathrm{f}_{\mathrm{V}}\left(\vartheta^{*}\right)\right]_{\text {STD }}$. As discussed below, the ratio $\mathrm{f}_{\mathrm{R}}(\mathrm{n}) /\left[\mathrm{f}_{\mathrm{R}}(\mathrm{n})\right]_{\text {STD }}$ will usually be unity if the scattering solution of interest and the standard have the same refractive index and neither attenuates the intensity significantly. Further, if the standard scattering is determined at 0 degree scattering angle, as from a turbid glass (see below), with the incident beam passing through the scattering cell, $\mathrm{f}_{\mathrm{EXT}}(\vartheta, \mu) /\left[\mathrm{f}_{\mathrm{EXT}}(\vartheta, \mu)\right]_{\mathrm{STD}}$ may be set to unity for cylindrical light scattering cells. Otherwise, these must be evaluated, along with all of the parameters in the the ratio $k(\mu, n, \vartheta) / k_{\text {STD }}\left(\mu, n, \vartheta^{*}\right)$.

\section{Optical Factors}

As detailed above, in some situations $\mathrm{k}(\mu, \mathrm{n}, \vartheta) / \mathrm{k}_{\mathrm{STD}}(\mu, \mathrm{n}, \vartheta)$ must be determined, requiring the evaluation of the several optical parameters defined in the preceding. Some details on this subject are given in the following paragraphs.

Volume and refraction effects. The dependence of the scattering volume $\mathrm{V}(\vartheta, \mathrm{n})$ on the scattering angle $\vartheta$ and solution refractive index $n$ depends on the optical arrangement of both incident and scattered rays. Under most circumstances, $V(\vartheta, n) \approx \widetilde{V}_{90} / f_{R}(n) f_{V}(\vartheta)$, where $\widetilde{V}_{90}$ is the hypothetical scattering volume at 90 degree scattering angle in the absence of refraction effects (i.e., the scattering volume that would obtain at 90 degree scattering angle in air), $\mathrm{f}_{\mathrm{R}}(\vartheta)$ accounts for refraction at the solution-glass::glass-air interfaces at the same angle, and $f_{V}(\vartheta)$ accounts for the variation of the scattering volume with angle. In the simplest case in which the entire scattering volume is illuminated uniformly in a cell with cylindrical symmetry, $f_{V}(\vartheta) \approx \sin (\vartheta)$ and $f_{R}(n) \approx n^{2}$ [3]. In general, however, it is necessary to determine $f_{R}(n) f_{V}(\vartheta) /\left[f_{R}(n) f_{V}(\vartheta)\right]_{S T D}$ by direct experiment for the optical arrangement in use, by measurement of the detector response for a system with known angular dependence of the response, and for which the factors $\mathrm{f}_{\mathrm{P}}(\vartheta)$ and $\mathrm{f}_{\mathrm{EXT}}(\vartheta, \mu)$ are known. The emission from a dilute fluorescent dye is convenient for this purpose, since the fluorescence emission does not depend on scattering angle, and may be isolated from light with the incident wavelength by the use of appropriate filters in the detector beam. Alternatively, the scattering from a low molecular weight polymer solution with negligible (but accurately known) angular dependence of the scattering may be used to determine $f_{R}(n) f_{V}(\vartheta) /\left[f_{R}(n) f_{V}(\vartheta)\right]_{\text {STD }}$. When using a different detector for each scattering angle, these measurements would give the product $\left\{\mathrm{f}_{\mathrm{CAL}}(\vartheta, \lambda) / \mathrm{f}_{\mathrm{CAL}}\left(\vartheta^{*}, \lambda\right)\right\}\left\{\mathrm{f}_{\mathrm{R}}(\mathrm{n}) \mathrm{f}_{\mathrm{V}}(\vartheta) /\left[\mathrm{f}_{\mathrm{R}}(\mathrm{n}) \mathrm{f}_{\mathrm{V}}(\vartheta)\right]_{\mathrm{STD}}\right\}$ needed to compute $\mathbf{R}(\mathrm{q})$ from $\mathrm{D}(\mathrm{q}) / \mathrm{D}_{\mathrm{STD}}$, see above. 
Optical Attenuation. In some cases, the extinction coefficient of the solution may be large enough that the decrease in the intensity of the incident and/or scattered rays is not negligible. The attenuation may occur through scattering or absorption. Provided the absorption is not too large, the attenuation may be taken into account through measurements of the extinction $\mu$ and the optical path length $(\vartheta)$ by the introduction of a factor $\mathrm{f}_{\mathrm{EXT}}(\vartheta, \mu)=\exp [\mu(\vartheta)]$. The value of $(\vartheta)$ may be determined for a particular solution and scattering cell by calculation based on the cell geometry (e.g., for a cylindrical cell of diameter D, $(\vartheta)=\mathrm{D})$, or may be determined by appropriate measurements [22]. The extinction factor will be the sum $\mu_{\mathrm{A}}+\tau_{\mathrm{S}}$ of the extinction factor $\mu_{\mathrm{A}}$ for absorption and the turbidity $\tau_{\mathrm{S}}$. The latter may be estimated from $\tau_{\mathrm{S}} \approx(16 \pi / 3) \mathbf{R}_{90}$, where $\mathbf{R}_{90}$ is the Rayleigh ratio observed at 90 degree scattering angle [3], and $\mu_{\mathrm{A}}$ may be determined independently for the solution. Inappropriate neglect of $\mathrm{f}_{\mathrm{EXT}}(\vartheta, \mu)$ can cause an error in the value of $\left(\mathrm{A}_{2}\right)_{\mathrm{LS}}$ deduced from the scattering behavior.

Polarization Factor. In many cases, the incident source is plane-polarized perpendicular to the scattering plane, with the scattered light with the same polarization state being isolated for detection, as assumed in presenting the relations for static scattering in the preceding. A factor $f_{P}(\vartheta)$ may be introduced to account for the effects of 'naturally polarized' incident light comprising components of vertically and horizontally polarized light in equal amounts: $\mathrm{f}_{\mathrm{P}}(\vartheta)=1 /\left\{1+\cos ^{2}(\vartheta)\right\}$. Other expressions may be required for alternative polarization states.

\section{Calibration Standard}

A variety of materials have been used as the standard in the preceding [3]. It is only necessary that the absolute value of $\mathbf{R}(\mathrm{q})$ be known by some method for the material that is to be used as the standard. In some cases, a pure liquid for which $\mathbf{R}(q)$ is accurately known is used as the standard (e.g., benzene). This suffers two potential disadvantages: (1) $\mathbf{R}(q)$ for the standard may be smaller than $\mathbf{R}(q)$ for the solution, and even smaller than $\mathbf{R}_{\mathrm{xs}}(\mathrm{q}, \mathrm{c})=[\mathbf{R}(\mathrm{q}, \mathrm{c})]_{\text {SOLN }}-[\mathbf{R}(\mathrm{q}, \mathrm{c})]_{\text {SOLVENT }}$ except at the lowest concentrations studied, limiting the accuracy of the result, and (2) care must be taken that impurities, especially fluorescent impurities, do not affect the measured signal for the standard. The use of the forward scattering from a turbid glass offers a means to increase the signal from the standard to a larger value, but again some disadvantages accrue to this method, which has been used in some cases: (1) the scattering from the turbid glass must itself be calibrated, and (2) the signal may vary by more than an acceptable amount if the glass is not precisely positioned in the same way with respect to the incident beam. The scattering from a polymer solution or a colloidal dispersion offers a means to minimize these disadvantages. In principal, the scattering from a colloidal dispersion with sufficient turbidity to permit accurate measurement of the transmission by measurements external to the light scattering apparatus offers a means 
to effect the calibration [3]. In practice it is not easy to obtain a system with particles small enough and sufficiently free of interparticle association that $\mathbf{R}_{\mathbf{x s}}(q)$ is independent of $\mathrm{q}$, permitting accurate evaluation of $\mathbf{R}_{\mathrm{xs}}(\mathrm{q})$ from the externally measured turbidity. Alternatively, the scattering from a polymeric solute of accurately known $\mathrm{M}_{w}$ and $\partial \mathrm{n} / \partial \mathrm{c}$ may be used for the calibration. This is particularly useful for an instrument with a single detector, so that $\mathrm{f}_{\mathrm{CAL}}(\vartheta, \lambda)=\mathrm{f}_{\mathrm{CAL}}(\lambda)$ is independent of $\vartheta$. Thus, for data extrapolated to zero scattering angle and infinite dilution:

$$
\mathrm{f}_{\mathrm{CAL}}(\lambda)=\mathrm{KM}_{\mathrm{w}} \lim _{\substack{\vartheta=0 \\ \mathrm{c}=0}}\left[\mathrm{cD}_{\mathrm{INC}} / \mathrm{D}_{\mathrm{xS}}(\mathrm{q}, \mathrm{c}) \mathrm{k}(\mu, \mathrm{n}, \vartheta)\right]
$$

with $\left.\mathrm{K}=\left(4 \pi^{2} / \mathrm{N}_{\mathrm{A}} \lambda^{4}\right)\{\mathrm{n} \partial \mathrm{n} / \partial \mathrm{c})_{\mu}\right\}^{2}$ for vertically polarized incident and scattered light.

\section{Sample Preparation}

The optical clarification of the scattering sample is of paramount importance in obtaining reliable results in light scattering. The clarification should remove extraneous motes ('dust'), undissolved polymer, gas bubbles, and any other scattering source not intrinsic to the sample of interest. At the same time, the clarification process should not cause unwanted removal of a portion of the sample. Often, in the final stages of clarification, the number of extraneous motes is very small, giving the appearance of a few widely separated bright spots in the sample when the scattering is viewed at a small scattering angle. In some instruments the scattering volume is made small in a strategy to reduce the number of extraneous particles in the scattering volume to zero or one for the most part owing to the wide separation of any remaining extraneous motes. Since the scattering will then normally be rather different for these two states, it is possible to discriminate against the scattering from the extraneous matter.

Methods of clarification include filtration and centrifugation. Filtration is usually through membrane filters under pressure, with filter porosity in the range 0.1 to 0.5 $\mu \mathrm{m}$. Care must be taken that the filtration does not degrade high molecular weight polymer. The use of light scattering as a detector for size exclusion chromatography can afford exceptionally effective method of clarification; an example of the permitting evaluation of the dependence of the scattering on angle for a low molecular weight polymer may be found in reference [23]. It is sometimes necessary to use centrifugation to clarify the solutions, e.g., if the solute is a very high molecular weight chain, filtration may degrade the macromolecule. Centrifugation is most effective if it can be effected directly in the light scattering cell using a swinging-bucket centrifuge rotor, see reference [3]. In some cases, it may be necessary to centrifuge the solution outside the 
light scattering cell, followed by transfer to the cell, but that should be avoided if at all possible.

Samples dissolved in a multicomponent solvent (e.g., an aqueous salt solution) should be dialyzed against the solvent prior to determination of the refractive index increment $(\partial \mathrm{n} / \partial \mathrm{c})_{\mu}$ at osmotic equilibrium of solvent components. The use of the refractive index increment $(\partial \mathrm{n} / \partial \mathrm{c})_{\mathrm{w}}$ prepared by weight instead of $(\partial \mathrm{n} / \partial \mathrm{c})_{\mu}$ in the computation of $\mathrm{K}$ will lead to erroneous values of $\mathrm{M}_{\mathrm{w}}$ unless the components in the solvent are isorefractive, in which case the dialysis is not necessary [3; 11]. 


\section{DATA TREATMENT}

\section{Static Scattering}

Several methods of data treatment may be found in the literature for both static and dynamic scattering. For static scattering from optically isotropic, compositionally uniform solute, the preceding expressions may be put in the form

$$
\left(\frac{\mathrm{Kc}}{\mathbf{R}(\mathrm{q}, \mathrm{c})}\right)=\left(\frac{1}{\mathrm{M}_{\mathrm{w}}}\right)\left\{1+\left(\mathrm{R}_{\mathrm{G}}^{2}\right)_{\mathrm{LS}} \mathrm{q}^{2} / 3+2 \mathrm{Q}_{\mathrm{LS}}(\mathrm{q})\left(\mathrm{A}_{2}\right)_{\mathrm{LS}} \mathrm{M}_{\mathrm{w}} \mathrm{c}+\ldots\right\}
$$

According to this expression, the initial tangents to $\mathrm{Kc} / \mathbf{R}(\mathrm{q}, \mathrm{c})$ as a function of $\mathrm{q}^{2}$ and $\mathrm{c}$ are given by

$$
\begin{aligned}
& \left(\frac{\partial[\mathrm{Kc} / \mathbf{R}(\mathrm{q}, \mathrm{c})]}{\partial \mathrm{q}^{2}}\right)_{\mathcal{c}}=(1 / 3)\left(\mathrm{R}_{\mathrm{G}}^{2}\right)_{\mathrm{LS}} / \mathrm{M}_{\mathrm{w}}+2\left(\mathrm{~A}_{2}\right)_{\mathrm{LS}} \mathrm{C}\left(\frac{\partial \mathrm{Q}_{\mathrm{LS}}(\mathrm{q})}{\partial \mathrm{q}^{2}}\right)_{\mathcal{c}}+\ldots \\
& \left(\frac{\partial[\mathrm{Kc} / \mathbf{R}(\mathrm{q}, \mathrm{c})]}{\partial \mathrm{c}}\right)_{\mathrm{q}}=2\left(\mathrm{~A}_{2}\right)_{\mathrm{LS}} \mathrm{Q}_{\mathrm{LS}}(\mathrm{q})+\ldots
\end{aligned}
$$

Consequently, if $\mathrm{Q}_{\mathrm{LS}}(\mathrm{q}) \approx 1$, as with flexible chain polymers to a good approximation, curves of $\mathrm{Kc} / \mathbf{R}(\mathrm{q}, \mathrm{c})$ versus $\mathrm{q}^{2}$ parametric in $\mathrm{c}$ are expected to be parallel, as are curves of $\mathrm{Kc} / \mathbf{R}(\mathrm{q}, \mathrm{c})$ versus c parametric in $\mathrm{q}^{2}$. This observation led to the well-known doubleextrapolation method of Zimm [3; 17], in which $\mathrm{Kc} / \mathbf{R}(\mathrm{q}, \mathrm{c})$ is plotted against $\mathrm{q}^{2}+\mathrm{kc}$, with $\mathrm{k}$ an arbitrary constant chosen to produce a useful spread in the plotted data. The use of this double-extrapolation procedure prohibits use of a plot of $[\mathrm{Kc} / \mathbf{R}(0, \mathrm{c})]^{1 / 2}$ versus $c$ discussed above as a means to improve the assessment of $\mathrm{M}_{\mathrm{w}}$ and $\left(\mathrm{A}_{2}\right)_{\mathrm{LS}}$. It also makes it impractical to make use of the method of Berry involving a plot of $\left\{[\mathrm{Kc} / \mathbf{R}(\mathrm{q}, \mathrm{c})]^{\mathrm{O}}\right\}^{1 / 2}$ versus $\mathrm{q}^{2}$ as discussed above to improve the estimation of $\left(\mathrm{R}_{\mathrm{G}}^{2}\right)_{\mathrm{LS}}$ for high molecular weight flexible chain molecules. Thus, for example,

$$
\frac{\partial[\mathrm{Kc} / \mathbf{R}(\mathrm{q}, \mathrm{c})]^{1 / 2}}{\partial \mathrm{q}^{2}}=(1 / 6)\left(\mathrm{R}_{\mathrm{G}}^{2}\right)_{\mathrm{LS}} \frac{\left(1-\left(\mathrm{A}_{2}\right)_{\mathrm{LS}} \mathrm{M}_{\mathrm{w}} \mathrm{c}\right)}{\mathrm{M}_{\mathrm{w}}}+\ldots
$$

so that plots of $\{[\mathrm{Kc} / \mathbf{R}(\mathrm{q}, \mathrm{c})]\}^{1 / 2}$ versus $\mathrm{q}^{2}$ parametric in $\mathrm{c}$ are not expected to be parallel (unless $\mathrm{A}_{2}=0$ ). Consequently, if the square-root function is to be examined, it is prudent to carry out separate extrapolations of $\{[\mathrm{Kc} / \mathbf{R}(\mathrm{q}, \mathrm{c})]\}^{1 / 2}$ versus $\mathrm{q}^{2}$ to deduce $[\mathrm{Kc} / \mathbf{R}(0, \mathrm{c})]^{1 / 2}$ and the tangents $\partial[\mathrm{Kc} / \mathbf{R}(\mathrm{q}, \mathrm{c})]^{1 / 2} / \partial \mathrm{q}^{2}$ for each concentration. These can then 
be extrapolated to infinite dilution to obtain the desired parameters, i.e., $\mathrm{M}_{\mathrm{w}^{\prime}}\left(\mathrm{A}_{2}\right)_{\mathrm{LS}}$ and $\left(\mathrm{R}_{\mathrm{G}}^{2}\right)_{\mathrm{LS}}$.

As discussed above, the effects of absorption by the scattering solution may be taken into account through the factor $\mathrm{f}_{\mathrm{EXT}}(\mu, \vartheta)$ (provided the absorption is not too severe). In some cases, the absorption is accompanied by fluorescence from the scattering solution. Although that effect may be essentially eliminated by placing a band-pass filter in the scattering beam, that is not always possible with commercial light scattering photometers. In such a case, the fluorescence must be determined independently and account taken of its contribution to the observed instrument response in the data analysis. If it is possible to arrange for horizontally polarized incident light, then the observed signal at 90 degree scattering angle will comprise contributions from the solvent scattering and the fluorescence, assuming negligible contribution from the solute, as would, for example, be the usual case for the scattering from flexible chain polymers. These data can then be used to estimate the fluorescence contribution with vertically polarized light.

In some cases, the experimental data encompass a limited range of angles (e.g., two or three), leading to the use of "dissymmetry methods" to analyze scattering data, following a procedure introduced early in the use of light scattering to characterize solute dimensions [24]. Typically, one of the scattering angles is taken to be 90 degrees. In the original dissymmetry method, data were also collected at 45 and 135 degrees to compute the dissymmetry $Z(45,135)$ as the ratio of $\mathbf{R}(\mathrm{q}, \mathrm{c})$ for these two angles. Use of supplementary angles will usually make the scattering volumes equal at the two scattering angles, simplifying the analysis. If the solute shape (conformation) is known, e.g., a random-flight linear chain, a sphere, etc., then the known functional form for $P_{L S}(q)$ for that model may be used to deduce $\left(R_{G}^{2}\right)_{L S} /(n \lambda)^{2}$, along with the correction needed to deduce $\mathbf{R}(0, \mathrm{c})$ from $\mathbf{R}(\mathrm{q}, \mathrm{c})$ determined at some particular angle, often 90 degrees. Tables to assist this treatment are available, e.g., see reference [14], or the needed relations may be readily calculated as required using a desktop computer. Care must be taken, however, that the assumed model is appropriate. For example, neglect of any molecular weight heterogeneity from data on $Z(45,135)$ may lead to error in the estimate of $\left(R_{G}^{2}\right)_{L S}$. Similarly, the use of $P_{L S}(q)$ for a linear chain to estimate $\left(R_{G}^{2}\right)_{L S} /(n \lambda)^{2}$ by the dissymmetry ratio for a chain that is branched may introduce an error in the estimate for $\left(R_{G}^{2}\right)_{L S}$ if $\left(R_{G}^{2}\right)_{L S} q^{2}$ exceeds about 1 . For example, the deviations shown in Figures 2 will correspond to increasingly serious overestimation of $\left(R_{G}^{2}\right)_{L S}$ with increasing $\left(R_{G}^{2}\right)_{L S} q^{2}$ unless the effects noted in Figure 2 are taken into account. An example of this effect may be seen for $Z(45,135)$ vs. $\left(R_{G}^{2}\right)^{1 / 2} / n \lambda$ for monodisperse linear 
chains and regular four-arm star branched molecules for the random-flight model [14]. In some cases, only two scattering angles are used, one being fairly small, say $\vartheta_{\text {Low }}$, and the other being 90 degrees [25;26]. With due attention to the scattering volume at these two angles, the dissymmetry $\mathrm{Z}\left(\vartheta_{\mathrm{LOW}}, 90\right)$ may be determined, and used as above to estimate $\left(R_{G}^{2}\right)_{L S}$, with similar stipulations for care in the treatment.

As mentioned above, $\mathrm{Q}_{\mathrm{LS}}(\mathrm{q})$ may deviate from unity, as with a spherical solute. This deviation does not, however, affect the initial tangent significantly, permitting its neglect for most purposes. For example, for a spherical solute with a uniform size, since $Q_{L S}(q)-1 \propto\left(R_{G}^{2} q^{2}\right)^{2}$, the deviation of $Q_{L S}(q)$ from will only be important at relatively large q. Finally, other methods of data treatment may be found in the literature. Examples include Guinier plots of $\ln (\mathbf{R}(\mathrm{q}, \mathrm{c}) / \mathrm{c}) \mathrm{vs} \mathrm{q}^{2}$, Porod plots of $\mathrm{q}^{2} \mathbf{R}(\mathrm{q}, \mathrm{c})$ vs q, and Casassa plots of $\mathrm{Kc} / \mathbf{R}(\mathrm{q}, \mathrm{c})$ vs q [3], either on a linear or bilogarithmic scale, but these are not recommended for analysis of data on dilute solutions except under special circumstances. Thus, the Casassa plot is useful for very long rodlike solute for which the asymptotic behavior for large q may dominate the scattering for all accessible q, in which case the tangent provides length per unit mass. Similarly, the Porod plot is designed to elucidate the behavior at large q, may, for example reveal the persistence length of a semiflexible (wormlike) chain if large enough q can be attained; the Porod plot is usually of most interest with the scattering from x-ray or neutron radiation owing to the need to reach large q. The Guinier plot was devised for use with the scattering from particles polydisperse in size and shape, for which a more detailed treatment was not feasible, and is consistent with the approximation $\mathrm{P}_{\mathrm{LS}}(\mathrm{q}) \approx \exp \left[-\left(\mathrm{R}_{\mathrm{G}}^{2}\right)_{\mathrm{LS}}\right.$ $\mathrm{q}^{2} / 3$ ] that must obtain in the limit of small $\mathrm{q}$. The actual scattering behavior is usually not represented by the exponential function over a range of $q$ (unless $\left(R_{G}^{2}\right)_{L S}$ is very small).

\section{Dynamic Scattering}

The treatment of dynamic scattering relies on the assumption that Eq. 9 is appropriate for the conditions studied. One deviation from this may occur, for example, if the scattering includes a component that is essentially stationary on the time scale studied. In this case, if the stationary signal contributes a fraction $r_{S}$ of the scattered intensity, then

$$
g^{(2)}(\tau ; q, c)=1+2 r_{s}(q)\left[1-r_{s}(q)\right] f_{C}^{1 / 2}|g(1)(\tau ; q, c)|+\left[1-r_{s}(q)\right]^{2} f_{C}\{g(1)(\tau ; q, c)\}^{2}
$$

Thus, if $r_{s}(q)$ approaches unity, the dynamic response no longer depends on $\left\{g^{(1)}(\tau ; q, c)\right\}^{2}$, but rather on $\left|g^{(1)}(\tau ; q, c)\right|$. Unfortunately, if $\left|g^{(1)}(\tau ; q, c)\right| \approx \exp [-\tau \gamma(q, c)]$, as would be 
expected for a solute with a narrow size distribution, this difference will not be obvious in the exponential response. However, the factor $2 r_{S}(q)\left[1-r_{S}(q)\right] f_{C}^{1 / 2}$ will be appreciably smaller than the coherence factor $\mathrm{f}_{\mathrm{C}}$ normally expected with the detector optics (e.g., the pinhole diameter in the detector optics), providing an alert to the presence of the changed nature of $\mathrm{g}^{(2)}(\tau ; \mathrm{q}, \mathrm{c})$. This circumstance can arise, for example, if the solution of an otherwise well dissolved solute also contains large aggregates, with appreciably smaller diffusion constant than that of the dissolved solute. It may be noted that an arrangement with a strong stationary signal is purposely employed in electrophoretic scattering in which an electric field is imposed on the sample [4;6]. In that case, the response is modulated by a cosine factor that contains information on the electrophoretic mobility.

The estimation of $\mathrm{G}^{(2)}(\infty ; \mathrm{q}, \mathrm{c})$ needed to compute $\mathrm{g}^{(2)}(\tau ; \mathrm{q}, \mathrm{c})$ is not always accurate. Indeed, some workers prefer to use an empirical parameter in place of $G^{(2)}(\infty ; q, c)$ :

$$
\mathrm{G}^{(2)}(\tau ; \mathrm{q}, \mathrm{c})=\mathrm{W}_{1}+\mathrm{W}_{2}\left\{\mathrm{~g}^{(1)}(\tau ; \mathrm{q}, \mathrm{c})\right\}^{2}
$$

with $W_{1}$ and $W_{2}$ chosen to fit the data to an exponential $g^{(1)}(\tau ; q, c)$. This procedure is not as desirable as the use of properly determined $\mathrm{G}^{(2)}(\infty ; \mathrm{q}, \mathrm{c})$. Finally, it should be noted that the relationship between $\mathrm{g}^{(1)}(\tau ; \mathrm{q}, \mathrm{c})$ and $\mathrm{g}^{(2)}(\tau ; \mathrm{q}, \mathrm{c})$ assumed in the preceding may fail under (unusual) circumstances [4;6], unexpected for systems of likely interest for the scattering from dilute solutions and dispersions.

Presuming that a reliable estimate has been obtained for $\mathrm{G}^{(2)}(\infty ; \mathrm{q}, \mathrm{c})$, and that there is no stationary scattering source, it is advisable to examine a plot of $\ln \left\{\mathrm{g}^{(2)}(\tau ; \mathrm{q}, \mathrm{c})-1\right\}$ versus $\tau$, or $\tau q^{2}$ if several angles are used. This will expose deviation from pure exponential behavior more clearly than the often used plot of $g^{(2)}(\tau ; q, c)-1$ versus $\tau$, and facilitate estimation of the initial tangent. In either case, a nonlinear curve fitting program can be used to obtain a cumulant fit to the data, or an inverse Laplace transform method (ILT) can be used for a more detailed analysis, e.g., see reference [20] for an example of a reasonably robust procedure. An example of an ILT analysis on data that was nonexponential is given in Figure 3 (from reference [27]). In this example, the data were analyzed with a limited number $\mathrm{n}$ of weighted exponential terms, with the ratio $\gamma_{\mu} / \gamma_{\mu-1}$ of successive relaxation rates $\gamma_{\mu}$ being a constant. The smallest $\gamma_{\mu}$, and the ratio $\gamma_{\mu} / \gamma_{\mu-1}$ (or equivalently $n$ ) were chosen to be consistent with the range of $\tau$ in the experimental data, and such that the analysis was stable, and the first cumulant $\mathrm{K}_{1}$ did not change on the use of smaller $\gamma_{\mu} / \gamma_{\mu-1}$ (or larger $n$ ). The process was completed eight times with differing smallest $\gamma_{\mu}$ and $n=5$ to produce the results in Figure 3. Even though any one of these five-term sets is sufficient to represent $\mathrm{g}^{(2)}(\tau ; \mathrm{q}, \mathrm{c})$, the collected 
eight sets present a useful qualitative characterization of the distribution of relaxation rates, revealing a bimodal distribution in the example cited. As mentioned above, since the inversion is formally ill-posed, algorithms to accomplish the inversion should be used with caution, and inaccuracies may accrue even when constraints are imposed to stabilize the inversion. Further, since the limitations on the minimum and maximum values of $\tau$ characterizing the experimental data, as well as the precision of the data may lead to spurious results in some cases, the results of the inversion should best be considered as an alternative representation of the data that may, or may not, be simply interpreted in terms of a distribution of actual scattering species. 


\section{EXAMPLES}

\section{Static Scattering and Size Exclusion Chromatography}

The availability of light scattering photometers for on-line analysis of the eluent in size exclusion chromatography provides a powerful tool to augment polymer analysis and characterization [28]. Since the solute concentration is usually very low in the eluent, it is normally assumed that $\mathbf{R}(\mathrm{q}, \mathrm{c}) \approx \mathrm{KcMP}_{\mathrm{LS}}(\mathrm{q})$, where $\mathrm{K}=\left(4 \pi^{2} / \mathrm{N}_{\mathrm{a}} \lambda^{4}\right)\{\mathrm{n}(\partial \mathrm{n} / \partial \mathrm{c})\}^{2}$. The high optical clarity of the eluent permits effective scattering measurements at lower solute concentration than normally possible with solutions clarified by simple filtration (the shedding of particulate impurities can be a problem in some cases). In some, but not all, cases, light scattering instruments used as on-line SEC detectors determine the scattering at small scattering angle, so that $\mathrm{P}_{\mathrm{LS}}(\mathrm{q}) \approx 1$, simplifying the analysis (but also limiting the information available). On-line photometers permitting measurement over a range of scattering angles are also available, allowing determination of $\left(\mathrm{R}_{\mathrm{G}}^{2}\right)_{\mathrm{LS}}$ as a function of $\mathrm{V}_{\mathrm{e}}$. In many cases, e.g., for linear homopolymers, the distribution of species at each $\mathrm{V}_{\mathrm{e}}$ will be narrow enough to be considered monodisperse, so that $\left(\mathrm{R}_{\mathrm{G}}^{2}\right)_{\mathrm{LS}} \approx \mathrm{R}_{\mathrm{G}}^{2}$ and $\mathrm{M}_{\mathrm{w}} \approx \mathrm{M}$. Since that may not be so in all cases, e.g., for branched chains or for copolymers, the subscript "e" will be used in this section to designate the appropriate average obtained over species at elution volume $\mathrm{V}_{\mathrm{e}}$; for a linear homopolymer, $\left(\mathrm{R}_{\mathrm{G}}^{2}\right)_{\mathrm{e}} \approx\left(\mathrm{R}_{\mathrm{G}}^{2}\right)_{\mathrm{LS}}$ and $\mathrm{M}_{\mathrm{e}} \approx \mathrm{M}_{\mathrm{w}}$.

In most applications for SEC, a light scattering detector provides an analog signal $\mathrm{A}\left(\mathrm{q}, \mathrm{c} ; \mathrm{V}_{\mathrm{e}}\right)=\mathrm{k}_{\mathrm{R}} \mathbf{R}(\mathrm{q}, \mathrm{c})$, usually for a limited number of scattering angles (note, that here $\mathbf{R}(\mathrm{q}, \mathrm{c})$ is not an excess quantity, but the total scattering, including the solvent contribution). The overall molecular weight $\mathrm{M}_{\mathrm{w}}$ of a compositionally homogeneous solute may be determined using a light scattering detector alone under certain circumstances provided that $k_{R}, \partial n / \partial c$, and the total mass $m_{S}$ of the injected solute are known. Thus, the chromatographic data give

$$
\mathrm{M}_{\mathrm{app}}=\left(1 / \mathrm{Kk}_{\mathrm{R}} \mathrm{m}_{\mathrm{s}}\right) \sum \mathrm{P}_{\mathrm{e}}(\mathrm{q}) \Delta \mathrm{A}\left(\mathrm{q}, \mathrm{c} ; \mathrm{V}_{\mathrm{e}}\right) \Delta \mathrm{V}\left(\mathrm{V}_{\mathrm{e}}\right)
$$

where the sum is over all $\mathrm{V}_{\mathrm{e}^{\prime}} \Delta \mathrm{V}\left(\mathrm{V}_{\mathrm{e}}\right)$ is the elution volume at $\mathrm{V}_{\mathrm{e}^{\prime}}$ and $\Delta \mathrm{A}\left(\mathrm{q}, \mathrm{c} ; \mathrm{V}_{\mathrm{e}}\right)=$ $\left\{\mathrm{A}\left(\mathrm{q}, \mathrm{c} ; \mathrm{V}_{\mathrm{e}}\right)-\left[\mathrm{A}\left(\mathrm{q}, \mathrm{c} ; \mathrm{V}_{\mathrm{e}}\right)\right]_{\mathrm{s}}\right\}$, with subscript 's' designating the signal from pure solvent. With light scattering detectors providing a signal at low scattering angle, $\mathrm{P}_{\mathrm{e}}(\mathrm{q}) \approx 1$, and $\mathrm{M}_{\mathrm{app}} \approx \mathrm{M}_{\mathrm{w}}$.

It is common to use a differential refractive index detector in SEC to monitor $\mathrm{c} \propto$ $\mathrm{n}-\mathrm{n}_{\mathrm{s}}$, so that an output $\mathrm{N}\left(\mathrm{V}_{\mathrm{e}}\right)=\mathrm{k}_{\mathrm{n}}\left(\mathrm{n}-\mathrm{n}_{\mathrm{s}}\right)_{\mathrm{e}}$ is obtained for each $\mathrm{V}_{\mathrm{e}}$, along with the analog signal from a light scattering detector. Calculation of the molecular weight for 
each $\mathrm{V}_{\mathrm{e}}$ requires an estimate for $(\partial \mathrm{n} / \partial \mathrm{c})_{\mathrm{e}}$. For a compositionally homogeneous eluent, such that $(\partial \mathrm{n} / \partial \mathrm{c})$ is independent of $\mathrm{V}_{\mathrm{e}}$, an estimate for $\partial \mathrm{n} / \partial \mathrm{c}$ may be determined independently, or may be estimated from $\left[\Sigma\left(n-n_{s}\right)_{i}\right] / c$ with the sum taken over the entire chromatogram provided $\mathrm{k}_{\mathrm{n}}$ is known, with $\mathrm{c}$ the concentration of the solution injected on the column. It should be noted that in most instruments, different light sources are used in refractometery and light scattering, leading to a possible error if these differ in wavelength, and $\partial \mathrm{n} / \partial \mathrm{c}$ depends on $\lambda$. Then, combining the data from the two detectors, $\mathrm{M}_{\mathrm{e}} \mathrm{P}_{\mathrm{e}}(\mathrm{q})=\left[1 / \mathrm{K}_{\mathrm{e}} \mathrm{k}_{\mathrm{R}}\right] \Delta \mathrm{A}\left(\mathrm{q}, \mathrm{c} ; \mathrm{V}_{\mathrm{e}}\right) / \mathrm{c}_{\mathrm{e}}$, where $\mathrm{c}_{\mathrm{e}}=\left\{\mathrm{N}\left(\mathrm{V}_{\mathrm{e}}\right)-\left[\mathrm{N}\left(\mathrm{V}_{\mathrm{e}}\right)\right]_{\mathrm{BG}}\right\} / \mathrm{k}_{\mathrm{n}}(\partial \mathrm{n} / \partial \mathrm{c})_{\mathrm{e}}$ is the concentration at $\mathrm{V}_{\mathrm{e}}$. If the light scattering detector provides a signal at small scattering angle, such that $\mathrm{P}_{\mathrm{e}}(\mathrm{q}) \approx 1$, then the data provide an estimate for $\mathrm{M}_{\mathrm{e}}$. In addition, if a multiple-angle light scattering photometer is used, $\left(R_{G}^{2}\right)_{e}$ may be determined for the sample at each $\mathrm{V}_{\mathrm{e}}$ from the dependence of $\Delta \mathrm{A}\left(\mathrm{q}, \mathrm{c} ; \mathrm{V}_{\mathrm{e}}\right)$ on the scattering angle using relations given above; it is not necessary to know $k_{R}$ or $(\partial n / \partial c)$ for this analysis provided that $\mathbf{R}_{\mathrm{xs}}(\mathrm{q}, \mathrm{c}) \approx \mathrm{KcMP}_{\mathrm{LS}}(\mathrm{q})$, as postulated (i.e., the concentration is low enough to neglect terms in $\mathrm{c}^{2}$ ).

If the light scattering detector provides data only at a few (two or three) angles, then the dissymmetry method discussed above may be used to estimate $\mathrm{P}_{\mathrm{e}}(\mathrm{q})$, provided an appropriate model for this purpose is available, permitting estimates of $M_{e}$ and $\left(R_{G}^{2}\right)_{e}$ as functions of $c_{e}$ for the eluent, that is, the molecular weight and size distributions.. The limitations of the dissymmetry method discussed the preceding should be considered when making use of these methods. If only the scattering at a single large scattering angle is available (say, 90 degrees) is utilized, then some additional information must be provided to determine $\mathrm{M}_{\mathrm{e}}$ from the light scatttering data on $\mathrm{M}_{\mathrm{e}} \mathrm{P}_{\mathrm{e}}(\mathrm{q})$. In one such method, the "universal calibration" for SEC is assumed, such that the species at each elution volume are assumed to have common $M_{e}[\eta]_{e}$, where $[\eta]$ is the intrinsic visocity, i.e., $V_{e}=V\left(M_{e}[\eta]_{e}\right)$. Then, given a model to relate $M_{e}[\eta]_{e}$ to $\left(R_{G}^{2}\right)_{e^{\prime}}$ such as the Flory-Fox relation $\mathrm{M}_{\mathrm{e}}\left[\eta_{\mathrm{e}} \approx \Phi^{\prime}\left[\left(\mathrm{R}_{\mathrm{G}}^{2}\right)_{\mathrm{e}}\right]^{3 / 2}\right.$ for linear flexible chain polymers, the light scattering data may be analyzed to estimate $\mathrm{M}_{\mathrm{e}}$ and $\left(\mathrm{R}_{\mathrm{G}}^{2}\right)_{\mathrm{e}}$.

The addition of a third detector to determine the differential viscosity $\eta-\eta_{s}$ provides additional information complement the light scattering data $\left(\eta\right.$ and $\eta_{s}$ are the viscoities of solution and solvent, respectively). Thus, with an signal $H\left(V_{e}\right)=k_{H}\left(\eta-\eta_{s}\right)_{e}$ from a differential viscometer, the average intrinsic viscosity $[\eta]_{e}=\left(\eta-\eta_{s}\right)_{e} / c_{e}$ may be determined for each $\mathrm{V}_{\mathrm{e}}$ as $\Delta \mathrm{H}\left(\mathrm{V}_{\mathrm{e}}\right)=\left\{\mathrm{H}\left(\mathrm{V}_{\mathrm{e}}\right)-\left[\mathrm{H}\left(\mathrm{V}_{\mathrm{e}}\right)\right]_{\mathrm{BG}}\right\} / \mathrm{k}_{\mathrm{H}} \mathrm{c}_{\mathrm{e}}$. These data may be used, for example, along with the light scattering from a single large angle to estimate both $\mathrm{M}_{\mathrm{e}}$ and $\left(\mathrm{R}_{\mathrm{G}}^{2}\right)_{\mathrm{e}}$ by the dissymmetry method as discussed in the preceding paragragph, 
with the assumption of universal calibration (i.e., without use of the function $\mathrm{V}_{\mathrm{e}}=$ $\left.\mathrm{V}\left(\mathrm{M}_{\mathrm{e}}[\eta]_{\mathrm{e}}\right)\right)$; the limitations and potential errors in this procedure should be evaluated in each case. For example, comparison of the measured $M_{e}[\eta]_{e}$ with values deduced from $\mathrm{V}_{\mathrm{e}}=\mathrm{V}\left(\mathrm{M}_{\mathrm{e}}[\eta]_{\mathrm{e}}\right)$ at each $\mathrm{V}_{\mathrm{e}}$ permits a consistency check--deviations could be caused by experimental errors in $\mathrm{M}_{\mathrm{e}^{\prime}} \mathrm{c}_{\mathrm{e}}$ and/or $[\eta]_{\mathrm{e}}$, or in the assumption that $\mathrm{V}_{\mathrm{e}}=\mathrm{V}\left(\mathrm{M}_{\mathrm{e}}[\eta]_{\mathrm{e}}\right)$.

An example of the use of multi-angle light scattering with SEC to study the dimensions of poly(di- $n$-hexylsilane), PDHS, and poly(phenyl- $n$--hexylsilane), PPHS is given in Figure 4 (from reference [29]). The upper panel gives $M_{e}$ and $\left(R_{G}^{2}\right)_{e}$ resulting from analysis of the multi-angle scattering data, and the lower panel gives the response from the differential refractive index detector, normalized to give the same peak response. As expected, the values of $\left(R_{G}^{2}\right)_{e}$ are the same at a given elution volume for the two polymers, but the values of $\mathrm{M}_{\mathrm{e}}$ differ. Analysis of these data permitted assessment of the difference in $\left(\mathrm{R}_{\mathrm{G}}^{2}\right) / \mathrm{M}$ for these polymers, revealing the substantially larger persistence length for PPHS, owing to the effects of the phenyl substituent. Another useful example is provided by the analysis and characterization of branched macromolecules offers a particularly useful example of the value of measurements of $\mathrm{M}_{\mathrm{e}^{\prime}}\left(\mathrm{R}_{\mathrm{G}}^{2}\right)_{\mathrm{e}}$ and $[\eta]_{\mathrm{e}}$ as functions of $\mathrm{c}_{\mathrm{e}}$. In addition to a direct estimate of the molecular weight distribution, analysis of the dependence of $\left(R_{G}^{2}\right)_{e}$ and $[\eta]_{e}$ on $M_{e}$ can facilitate an assessment of branching in a sample. An example of this sort is given in reference [30].

\section{Intermolecular Association}

Depending on its nature, intermolecular association may complicate the analysis of static light scattering data, and its presence may be difficult to assess, depending on its character. In some cases, the molecular weight deduced from extrapolation of $\mathrm{Kc} / \mathbf{R}(\mathrm{q}, \mathrm{c})$ to zero $\mathrm{q}$ and infinite dilution will depend on temperature or solvent, revealing the association. An example of this sort in which the nature of intermolecular association of a solute with a helical conformation was elucidated by the use of static and dynamic light scattering as a function of temperature is given in reference [31]. In the cited case, the scattering at any given temperature exhibited 'normal' behavior, and could not have been analyzed to reveal association if taken alone. In a different and somewhat unusual, but not unique, example, it has been reported that $\mathrm{Kc} / \mathbf{R}(\mathrm{q}, \mathrm{c})$ is linear in $\mathrm{q}^{2}$, albeit giving a molecular weight that is much larger than the true value of $M_{w}$ for the solute [32]. This was observed with a system that formed a gel at a higher solute concentration, suggesting that the observed scattering behavior reflects the anticipated $\mathrm{P}_{\mathrm{LS}}(\mathrm{q})$ for a randomly branched polymer [15]. More frequently, with intermolecular association involving flexible chain polymers, $\mathrm{Kc} / \mathbf{R}(\mathrm{q}, \mathrm{c})$ exhibits enhanced scattering at small q. This is often taken as evidence for the presence of an aggregated species mixed 
with solute that is either fully dissociated, or much less aggregated. Although reasonable, it should be realized that such an interpretation is not unique. Analysis of such behavior with both static and dynamic scattering is then facilitated by the approximate representation with 'pseudo components', each of which dominates the scattering over a limited range of $\mathrm{q}$. Thus, it is assumed that

$$
\begin{aligned}
\mathbf{R}(\mathrm{q}, \mathrm{c}) & =\sum \mathbf{R}_{\mu}(\mathrm{q}, \mathrm{c}) \\
\mathrm{g}^{(1)}(\tau ; \mathrm{q}, \mathrm{c}) & =\sum \mathrm{r}_{\mu}(\mathrm{q}, \mathrm{c}) \exp \left[-\tau \gamma_{\mu}(\mathrm{q}, \mathrm{c})\right]
\end{aligned}
$$

with $\mathrm{r}_{\mu}(\mathrm{q}, \mathrm{c})=\mathbf{R}_{\mu}(\mathrm{q}, \mathrm{c}) / \mathbf{R}(\mathrm{q}, \mathrm{c})$, where $\mathbf{R}(\mathrm{q}, \mathrm{c})$ and $\mathrm{g}^{(1)}(\tau ; \mathrm{q}, \mathrm{c})$ are the functions observed at $\mathrm{q}$ and c. Analysis of $\mathrm{g}^{(1)}(\tau ; \mathrm{q}, \mathrm{c})$ then provides information on $\mathrm{r}_{\mu}(\mathrm{q}, \mathrm{c})$ and $\mathrm{a}_{\mathrm{LS}, \mu}(\mathrm{c})=$ $\mathrm{kTq}^{2} / 6 \pi \eta_{s} \gamma_{\mu}(\mathrm{q}, \mathrm{c})$ for each component. Similarly, analysis of $\mathbf{R}_{\mu}(\mathrm{q}, \mathrm{c})=\mathrm{r}_{\mu}(\mathrm{q}, \mathrm{c}) \mathbf{R}(\mathrm{q}, \mathrm{c})$

provides estimates of $\mathrm{w}_{\mu}\left(\mathrm{M}_{\mathrm{w}}\right)_{\mu}$ and $\left(\mathrm{R}_{\mathrm{G}}^{2}\right)_{\mathrm{LS}, \mu}$ for each pseudo component, where $\mathrm{w}_{\mu}$ is the weight fraction of that component. Comparison of $\left(R_{G}^{2}\right)_{L S, \mu}$ and $a_{L S, \mu}(c)$ can provide insight on the nature of the component. Further, in some cases, it may be reasonable to estimate $\left(\mathrm{M}_{\mathrm{w}}\right)_{\mu}$ for the component with smallest $\left(\mathrm{M}_{\mathrm{w}}\right)_{\mu}$ with the assumption that $\mathrm{w}_{\mu} \approx 1$ for that component, i.e., the scattering at small q reflects a small fraction of a large component. An example of a treatment of this kind may be found in reference [33]. In some cases, the depolarized scattering can be particularly useful if the association induces order in the aggregated species, e.g., see references [34;35].

\section{Scattering with Charged Species}

In some cases, the polymeric and colloidal scattering species may bear electric charge. Synthetic polyelectrolytes will usually bear either anionic or cationic charge, but many biological macromolecules are amphoteric. The electrostatic interactions among the scatterers can affect the dependence of $\mathbf{R}(\mathrm{q}, \mathrm{c})$ and $\mathrm{G}^{(2)}(\tau ; \mathrm{q})$ on concentration, and the electrostatic interactions among the chain elements can affect the dimensions of flexible chain polymers, affecting the dependence of $\mathbf{R}(\mathrm{q}, \mathrm{c})$ and $\mathrm{G}^{(2)}(\tau ; \mathrm{q})$ on $\mathrm{q}$. In the extreme case with the charged solute in an aqueous solution of pure water, these interactions may lead to interactions with a very long coherence length, making it impossible to apply the relations discussed in the preceding (it is possible, for example, to develop an ordered mesophase of charged spherical solute dispersed in pure water). Fortunately, the conditions for light scattering on such materials to deduce the molecular parameters discussed in the preceding are well developed $[3 ; 6 ; 11]$. Thus, the effects of electrostatic interactions on $\mathbf{R}(q, c)$ and $G^{(2)}(\tau ; q)$ may be screened by the presence of supporting simple electrolyte in the solution, thereby permitting application of the relations presented in the preceding, with one stipulation: the refractive index 
increment $(\partial \mathrm{n} / \partial \mathrm{c})_{\mu}$ needed to analyze $\mathbf{R}(\mathrm{q}, \mathrm{c})$ must be determined for the solution in osmotic equilibrium with the solvent containing the supporting electrolyte [3; 6].

Measurement $(\partial \mathrm{n} / \partial \mathrm{c})_{\mu}$ of can be achieved by equibrating the solution with the mixed solvent through a membrane of the kind used in measurements of the osmotic pressure. The same procedure must be made with any mixed solvent with components of different refractive index, e.g., a mixed solvent comprising two organic liquids.

As may be realized, an aqueous solution of an organic solute is often close to the conditions for intermolecular association, either equilibrium or metastable. Thus, with amphoteric proteins, it is often found that association will occur if the $\mathrm{pH}$ is adjusted to the isoelectric point, a condition for which appreciable numbers of anionic and cationic sites coexist on the chain. For a $\mathrm{pH}$ far from the isoelectric point, the amphoteric macromolecule behaves as either an anionic or cationic polyelectrolyte, and the net charge can help stablize the solution against association. The Debye screening length $\kappa^{-1}$ provides an important measure of the concentration of the supporting electrolyte, where

$$
\kappa^{-1}=\left(8 \pi \mathrm{N}_{\mathrm{A}} \mathrm{L}_{\mathrm{B}} \mathrm{I}_{0}\right)^{-1 / 2}
$$

with $\mathrm{I}_{0}=\sum \mathrm{z}_{\mu}^{2} \mathrm{~m}_{\mu} / 2$ the ionic strength derived from the small molecule electrolytes in the solution $\left(\mathrm{m}_{\mu}\right.$ being the molar concentration ( $\mathrm{mol} / \mathrm{mL}$ in cgs units) of species $\mu$ with charge $\mathrm{z}_{\mu}$ ), and $\mathrm{L}_{\mathrm{B}}=\mathrm{e}^{2} / \varepsilon \mathrm{kT}$ the Bjerrum length, with $\varepsilon$ the dielectric strength of the solvent and e the charge on an electron $\left(\mathrm{L}_{\mathrm{B}} / \mathrm{nm} \approx 57 / \varepsilon\right.$ at $25^{\circ} \mathrm{C}$, or $\mathrm{L}_{\mathrm{B}} \approx 0.7 \mathrm{~nm}$ for water, and $\kappa^{-1} / \mathrm{nm} \approx\left(4 \cdot 57 \pi \mathrm{N}_{\mathrm{A}} \sum \mathrm{z}_{\mu}^{2} \mathrm{~m}_{\mu} / \varepsilon\right)^{-1 / 2}$, or $\kappa^{-1} / \mathrm{nm} \approx\left(430 \sum \tilde{\mathrm{m}}_{\mu} / \varepsilon\right)^{-1 / 2}$ for univalent charge and molarity $\left.\tilde{\mathrm{m}}_{\mu}(\mathrm{mol} / \mathrm{L})\right)$, so that $\mathrm{\kappa}^{-1} / \mathrm{nm} \approx 0.42 /\left(\sum \tilde{\mathrm{m}}_{\mu}\right)^{1 / 2}$ for an aqueous solution of univalent charged simple electrolyte. With polyelectrolyte macromolecules, it is often convenient to adjust the supporting electrolyte composition to a level such that $\mathrm{K}^{-1}$ is comparable to the geometric dimensions of a chain element. In that case, the thermodynamic diameter $\mathrm{d}_{\mathrm{T}}$ appearing, for example in expressions for $\mathrm{A}_{2}$ will not be dominated by the electrostatic interactions among chains, and the effects of intramolecular electrostatic interactions on the chain dimensions will be largely suppressed [19;36] . 


\section{REFERENCES}

1 van de Hulst, H. C. Light scattering by small particles; Dover; New York, 1957.

2 Kerker, Milton The scattering of light, and other electromagnetic radiation Physical chemistry, v. 16; Academic Press; New York, 1969.

3 Casassa, Edward F.; Berry, Guy C. "Light scattering from solutions of macromolecules" In Polym Mol Weights, Pt. 1; P. E. Slade Jr., ed.; Vol. 4; Marcel Dekker, Inc; New York, 1975; 161-286.

4 Berne, B. J.; Pecora, R. Dynamic light scattering; John Wiley \& Sons, Inc.; New York, 1976.

5 Dahneke, B. E., ed. Measurement of suspended particles by quasi-elastic light scattering; Wiley-Interscience; New York, 1983.

6 Berry, G. C. "Light scattering" In Encyclopedia of Polymer Science and Engineering; H. Mark et al, ed.; Vol. 8; John Wiley \& Sons; New York, 1987; 721-94.

7 Schmitz, Kenneth S. An introduction to dynamic light scattering by macromolecules; Academic Press; Boston, 1990.

8 Chu, Benjamin Laser light scattering; 2nd ed.; Academic Press, Inc.; Boston, 1991.

9 Yamakawa, H. Modern theory of polymer solutions; Harper and Row; New York, 1971.

10 Huglin, M. B., ed. Light scattering from polymer solutions; Academic Press; London, 1972.

11 Eisenberg, H. Biological macromolecules and polyelectrolytes in solution Monographs on Physical Biochemistry, W. F. Harrington; A. R. Peacocke, eds.; Oxford Univ. Press; London, 1976.

12 Berry, G. C. "Static and dynamic light scattering on moderately concentrated solutions: Isotropic solutions of flexible and rodlike chains and nematic solutions of rodlike chains" Adv. Polym. Sci. 1994, 114, 233-90.

13 Brown, W., ed. Dynamic light scattering Monographs on the Physcis and Chemistry of Materials No. 49; Clarendon Press; Oxford, UK, 1993.

14 Casassa, E. F. "Particle scattering factors in Rayleigh scattering" In Polymer Handbook; E. H. Immergut; J. Branderup, eds.; John Wiley \& Sons; New York, 1989; pp. VII/485-91.

15 Burchard, W. "Static and dynamic light scattering from branched polymers and biopolymers" Adv. Polym. Sci. 1983, 48, 1-124.

16 Berry, G. C. "Molecular weight distribution" In Encyclopedia of Materials Science and Engineering; M. B. Bever, ed.; Pergamon Press; Oxford, 1986; 3759-68.

17 Zimm, B. H. "Apparatus and methods for measurement and interpretation of the angular variation of light scattering; Preliminary results on polystyrene solutions" J. Chem. Phys. 1948, 16, 157-74. 
18 Guinier, A.; Fournet, G. Small-angle scattering of $x$-rays; John Wiley \& Sons, Inc.; New York, 1955.

19 Casassa, E. F.; Berry, G. C. "Polymer solutions" In Comprehensive Polymer Science; G. Allen, ed.; Vol. 2; Pergamon Press; New York, 1988; Chapt. 3.

20 Ostrowsky, N.; Sornette, D.; Parker, R.; Pike, E. R. "Exponential sampling method for light scattering polydispersity analysis" Opt. Acta 1981, 28, 1059-70.

21 Kim, S. H.; Ramsay, D. J.; Patterson, G. D. "Static and dynamic light scattering of poly( $\alpha-$ methyl styrene) in toluene in the dilute region" J. Polym. Sci.: Pt. B: Polym. Phys. 1990, 28, 2023-56.

22 Berry, G. C. "Dilute and Concentrated Solutions of a Heterocyclic Polymer (BBB)" Disc. Faraday Soc. 1970, 49, 121.

23 Cotts, P. M. "Determination of molecular weight and radius of gyration of very low and high M polystyrene using SEC/LS" Prepr. Polym. Mat. Sci. Eng., Am. Chem. Soc. 1997, 77, 44-5.

24 Stacey, K. A. Light-scattering in physical chemistry; AcademicPress; New York, 1956.

25 Frank, R.; Frank, L.; Ford, N. C. "Molecular characterization using a unified refractiveindex-light-scattering intensity detector" In Chromatographic characterization of polymers : hyphenated and multidimensional techniques; Theodore Provder; Howard G. Barth; Marek W. Urban, eds.; American Chemical Society; Washington, DC, 1995; 109-21.

26 Mourey, T. H.; Coll, H. "Size-exclusion chromatography with light-scattering detection at two angles" In Chromatographic characterization of polymers : hyphenated and multidimensional techniques; Theodore Provder; Howard G. Barth; Marek W. Urban, eds.; American Chemical Society; Washington, DC, 1995; 123-40.

27 Yue, S.; Berry, G. C. "Moderately concentrated solution of polystyrene. Part 5. Static and dynamic light scattering in bis(2-ethylhexyl) phthalate" Macromol. Symp. 1995, 98, 100527.

28 Provder, Theodore; Barth, Howard G.; Urban, Marek W., eds. Chromatographic characterization of polymers: hyphenated and multidimensional techniques Advances in chemistry series 237; American Chemical Society; Washington, DC, 1995.

29 Cotts, P. M. "Comparison of the molecular dimensions of di-alkyl and aryl-alkyl-subsitutued polysilanes in solution using SEC/LS" J. Polym. Sci.: Pt. B: Polym. Phys. 1994, 32, 771-8.

30 Jackson, Christian; Chen, Yuan-Ju; Mays, Jimmy W. "Dilute solution properties of randomly branched poly(methyl methacrylate)" J. Appl. Polym. Sc. 1996, 59(1), 179-88.

31 Yue, S.; Berry, G. C.; Green, M. S. "Intermolecular association and supramolecular organization in dilute solution. 2. Light scattering and optical activity of poly(pbiphenylmethyl-L-glutamate" Macromolecules 1996, 29, 6175-82. 
32 Tanner, D. W.; Berry, G. C. "Properties of cellulose acetate in solution. I. Light scattering, osmometry and viscometry on dilute solutions" J. Polym. Sci.: Polym. Phys. Ed. 1974, 12, 941.

33 Einaga, Y.; Berry, G. C. "Studies on dilute solutions of rodlike macroions: III. Integrated intensity and photon correlation lightscattering investigation of association" In Microdomains in Polymer Solutions; P. Dubin, ed.; Plenum Press; New York, 1985; 191-210.

34 Furukawa, R.; Berry, G. C. "Studies on dilute solutions of rodlike macroions. 4. Aggregation with enhanced orientational correlation" Pure Appl. Chem. 1985, 57, 913-20.

35 Yue, S.; Berry, G. C.; McCullough, R. D. "Intermolecular association and supramolecular organization in dilute solution. 1. Regioregular poly(3-dodecylthiophene)" Macromolecules 1996, 29(3), 933-9.

36 Sullivan, V. J.; Berry, G. C. "Light scattering studies on dilute solutions of semiflexible polyelectrolytes" Intl. J. Polym. Anal. Charact. 1995, 2, 55-69.

37 Yamakawa, H.; Fujii, M. "Light scattering from wormlike chains. Determination of the shift factor" Macromolecules 1974, 7, 649-54. 


\section{APPENDIX}

Expressions for $\mathrm{P}(\mathrm{q})$ are given in the literature for a wide variety of model scattering moieties $[1-3 ; 6 ; 14 ; 15 ; 37]$. Several that find frequent use are are given by the relations, for monodisperse, isotropic scatterers:

$$
\begin{aligned}
\text { random-flight linear coil: } & \mathrm{P}(\mathrm{q})=\left(2 / \mathrm{u}^{2}\right)[\mathrm{u}-1+\exp (-\mathrm{u})] \\
\text { rod ("infinitely thin"): } & \mathrm{P}(\mathrm{q})=\left(2 / \mathrm{x}^{2}\right)[\mathrm{xSi}(\mathrm{x})-1+\cos (\mathrm{x})] \\
\text { disk ("infinitely thin"): } & \mathrm{P}(\mathrm{q})=\left(2 / \mathrm{z}^{2}\right)\left[1-\mathrm{J}_{1}(2 \mathrm{z}) / \mathrm{z}\right] \\
\text { sphere: } & \mathrm{P}(\mathrm{q})=\left(9 / \mathrm{y}^{6}\right)[\sin (\mathrm{y})-\mathrm{y} \cos (\mathrm{y})]^{2}
\end{aligned}
$$

Here, $\operatorname{Si}(\ldots)$ and $\mathrm{J}_{1}(\ldots)$ are the sine integral and the Bessel function of 1st order, respectively, and $u=R_{G}^{2} q^{2}, x^{2}=12 u, z^{2}=2 u$, and $y^{2}=5 u / 3$. The availability of desk-top computers makes it convenient to compute $\mathrm{P}(\mathrm{q})$ as needed in most cases, as opposed to the use of the same information in tabular form (rational approximations are available for the sine integral and the Bessel functions, e.g., see reference [14]).

Molecular weight dispersion modifies $\mathrm{P}_{\mathrm{LS}}(\mathrm{q})$ for each of these models. Thus,

$$
\mathrm{P}_{\mathrm{LS}}(\mathrm{q})=\mathrm{M}_{\mathrm{w}}^{-1} \sum \mathrm{w}_{\mu} \mathrm{M}_{\mu} \mathrm{P}_{\mu}(\mathrm{q})
$$

For example, for random-flight linear chains, using $\mathrm{P}(\mathrm{q})$ from above,

$$
\mathrm{P}_{\mathrm{LS}}(\mathrm{q})=\left[2 \mathrm{M}_{\mathrm{n}} / \mathrm{M}_{\mathrm{w}} \mathrm{u}_{\mathrm{n}}\right]\left\{1-\left(1 / \mathrm{u}_{\mathrm{n}}\right)\left[1-\sum \mathrm{w}_{\mu}\left(\mathrm{M}_{\mathrm{n}} / \mathrm{M}_{\mu}\right) \exp \left(-\mathrm{u}_{\mathrm{n}} \mathrm{M}_{\mu} / \mathrm{M}_{\mathrm{n}}\right)\right]\right\}
$$

where $u_{n}=\left(R_{G}^{2} / M\right) M_{n} q^{2}$. Further analysis requires stipulation of an expression for $w_{\mu}$. A number of commonly used expressions are given in reference [16]. For example, using the Schulz-Zimm (two-parameter exponential) distribution function [16; 17]

$$
P_{L S}(q)=\left[2 h /(1+h) u_{n}\right]\left\{1-\left(1 / u_{n}\right)\left[1-\left(1+u_{n} / h\right)^{-h}\right]\right\}
$$

where $\mathrm{h}^{-1}=\left(\mathrm{M}_{\mathrm{w}} / \mathrm{M}_{\mathrm{n}}\right)-1$ (note that the exponent "-h" erroneously appeared as " $h$ " in equation at the end of section 3.2 in reference [16]). This expression reduces to Eqn. 6 of the text for $h=1$, and to Eqn. $4 \mathrm{~b}$ for arbitrary $h$. 


\section{Table 1}

\section{Advantages/Disadvantages of Light Scattering}

\begin{tabular}{l|l}
\hline \multicolumn{1}{c|}{ Advantages } & \multicolumn{1}{c}{ Disadvantages } \\
\hline \hline $\begin{array}{l}\text { Capable of absolute measurements of } \\
\text { several parameters of interest } \\
\text { (molecular weight, mean square radius } \\
\text { of gyration, translational diffusion } \\
\text { coefficient, second virial coefficient). }\end{array}$ & $\begin{array}{l}\text { Requires a solvent with a different } \\
\text { refractive index than the solute (or } \\
\text { dispersed particle), scrupulous removal } \\
\text { of extraneous scattering moieties } \\
\text { ("dust"), and may require dialysis of } \\
\text { solutes in a mixed solvent (e.g., an } \\
\text { aqueous salt solution). }\end{array}$ \\
\hline $\begin{array}{l}\text { Useful over a very wide range of } \\
\text { molecular weight and provides well- } \\
\text { defined average properties of } \\
\text { heterodisperse polymers }\end{array}$ & $\begin{array}{l}\text { Analysis may be difficult with } \\
\text { copolymers, and may not be suitable for } \\
\text { very low molecular weight solute or } \\
\text { with strongly absorbing systems. }\end{array}$ \\
\hline $\begin{array}{l}\text { May be utilized as an on-line detector in } \\
\text { chromatographic separateions, such as } \\
\text { for size exclusion chromatography }\end{array}$ & $\begin{array}{l}\text { All of the above limitations apply } \\
\text { May be able to elucidate intermolecular } \\
\text { association in solution. }\end{array}$ \\
\hline
\end{tabular}




\section{Table 2}

\section{Light Scattering Average Mean-Square Radius of Gyration and Hydrodynamic Radius}

\begin{tabular}{|l|l|l|}
\hline & \multicolumn{1}{|c|}{$\left(\mathrm{R}_{\mathrm{G}}^{2}\right)_{\mathrm{LS}}$} & $\left.\mathbf{R}_{\mathrm{H}}\right)_{\mathrm{LS}}$ \\
\hline Exact Relation $^{\mathrm{a}}$ & $\left(1 / \mathrm{M}_{\mathrm{w}}\right) \Sigma_{\mathrm{w}_{\mu} \mathrm{M}_{\mu}\left(\mathrm{R}_{\mathrm{G}}^{2}\right)_{\mu}}$ & $\mathrm{M}_{\mathrm{w}} / \Sigma \mathrm{w}_{\mu} \mathrm{M}_{\mu}\left(\mathrm{R}_{\mathrm{H}}^{-1}\right)_{\mu}$ \\
\hline $\begin{array}{l}\text { Approximation for } \\
\mathrm{R}_{\mathrm{H}} \propto \mathrm{R}_{\mathrm{G}} \propto \mathrm{M}^{\varepsilon / 2}\end{array}$ & $\left(\mathrm{R}_{\mathrm{G}}^{2} / \mathrm{M}^{\varepsilon}\right) \mathrm{M}_{(\varepsilon+1)}^{\varepsilon+1} / \mathrm{M}_{\mathrm{w}}$ & $\left(\mathrm{R}_{\mathrm{H}} / \mathrm{M}^{\varepsilon / 2}\right) \mathrm{M}_{\mathrm{w}} / \mathrm{M}_{(1-\varepsilon / 2)}^{1-\varepsilon / 2}$ \\
\hline $\begin{array}{l}\text { Random-flight coil }^{\mathrm{c}} ; \\
\varepsilon=1\end{array}$ & $\left(\mathrm{R}_{\mathrm{G}}^{2} / \mathrm{M}\right) \mathrm{M}_{\mathrm{z}}$ & $\begin{array}{l}\left(\mathrm{R}_{\mathrm{H}} / \mathrm{M}^{1 / 2}\right) \mathrm{M}_{\mathrm{w}} / \mathrm{M}_{(1 / 2)}^{1 / 2} \\
\approx\left(\mathrm{R}_{\mathrm{H}} / \mathrm{M}^{1 / 2}\right) \mathrm{M}_{\mathrm{w} .}^{1 / 2}\left(\mathrm{M}_{\mathrm{w}} / \mathrm{M}_{\mathrm{n}}\right)^{0.10}\end{array}$ \\
\hline $\begin{array}{l}\text { Rodlike chain }^{\mathrm{c}} ; \\
\varepsilon \approx 2\end{array}$ & $\left(\mathrm{R}_{\mathrm{G}}^{2} / \mathrm{M}^{2}\right) \mathrm{M}_{\mathrm{z}} \mathrm{M}_{\mathrm{z}+1}$ & $\left(\mathrm{R}_{\mathrm{H}} / \mathrm{M}\right) \mathrm{M}_{\mathrm{w}}$ \\
\hline $\begin{array}{l}\text { Sphere } \\
\varepsilon=2 / 3\end{array}$ & $\left(\mathrm{R}_{\mathrm{G}}^{2} / \mathrm{M}^{2 / 3}\right) \mathrm{M}_{(5 / 3)}^{5 / 3} / \mathrm{M}_{\mathrm{w}}$ & $\left(\mathrm{R}_{\mathrm{H}} / \mathrm{M}^{1 / 3}\right) \mathrm{M}_{\mathrm{w}} / \mathrm{M}_{(2 / 3)}^{2 / 3}$ \\
$\approx\left(\mathrm{R}_{\mathrm{G}}^{2} / \mathrm{M}^{2 / 3}\right) \mathrm{M}_{\mathrm{z}}^{2 / 3}\left(\mathrm{M}_{\mathrm{w}} / \mathrm{M}_{\mathrm{z}}\right)^{0.10}$ & $\approx\left(\mathrm{R}_{\mathrm{H}} / \mathrm{M}^{1 / 3}\right) \mathrm{M}_{\mathrm{w} .}^{1 / 3}\left(\mathrm{M}_{\mathrm{w}} / \mathrm{M}_{\mathrm{n}}\right)^{0.10}$ \\
\hline
\end{tabular}

(a) For optically isotropic solute, and with $\partial \mathrm{n} / \partial \mathrm{c}$ the same for all scatterers

(b) $\mathrm{M}_{(\alpha)}=\left(\sum \mathrm{w}_{\mu} \mathrm{M}_{\mu}^{\alpha}\right)^{1 / \alpha}$

(c) Approximations are for a solute with a Schulz-Zimm (two-parameter exponential) distribution of $\mathrm{M}$, for which $\mathrm{M}_{(\alpha)} \approx \mathrm{M}_{\mathrm{w}}\{\Gamma(1+\mathrm{h}+\alpha) / \Gamma(1+\mathrm{h})\}^{1 / \alpha} /(1+\mathrm{h})$, see [16]. 


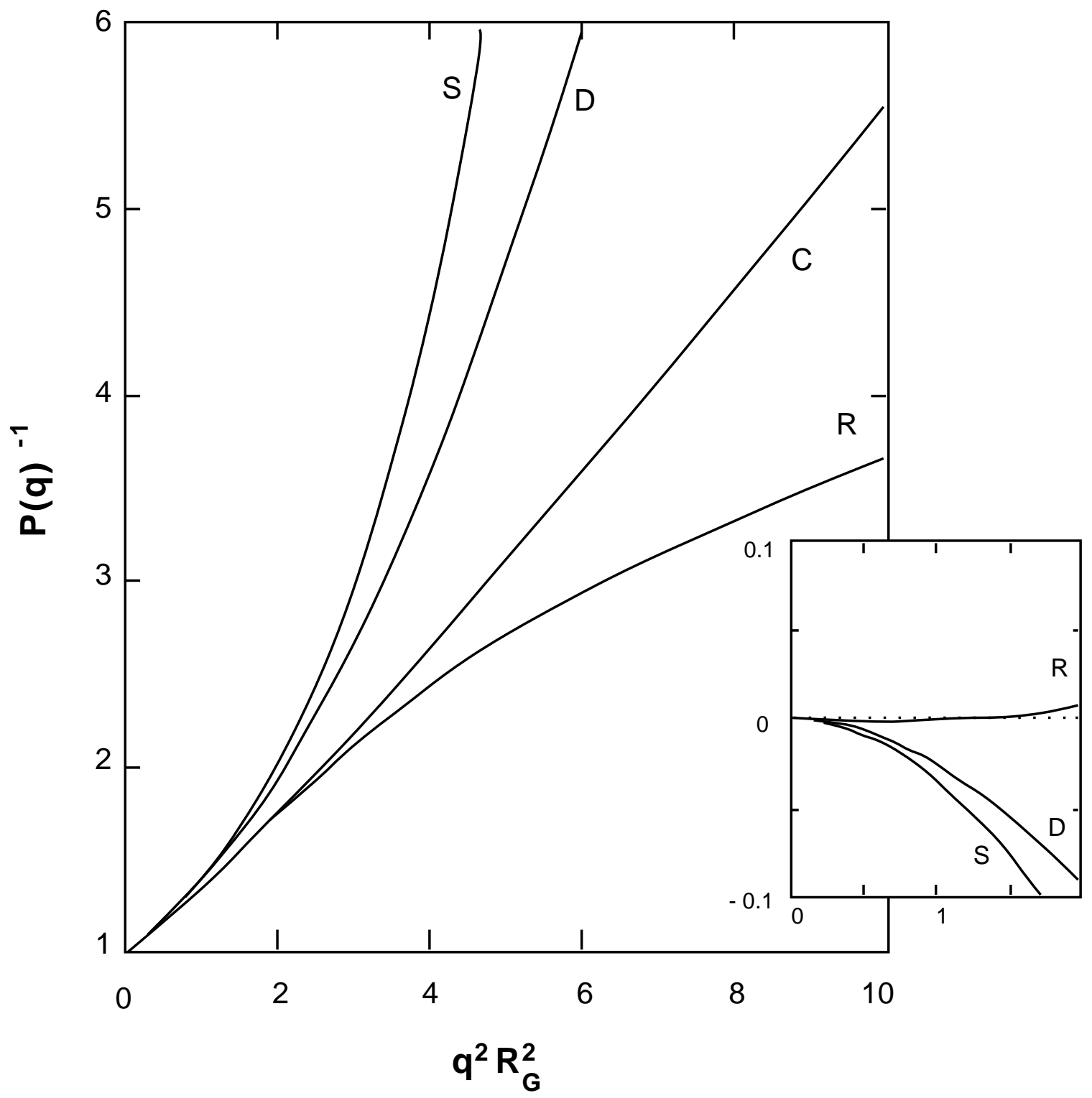

Figure 1 Examples of $\mathrm{P}(\mathrm{q})^{-1}$ versus $\mathrm{R}_{\mathrm{G}}^{2} \mathrm{q}^{2}$ for random-flight linear chains $(\mathrm{C})$, rodlike chains (R), disks (D) and spheres (S); expressions for $\mathrm{P}(\mathrm{q})$ for these cases are given in the Appendix. The insert shows the ratio of the logarithm of $\mathrm{P}(\mathrm{q})$ divided by $\mathrm{P}(\mathrm{q})$ for the coil with the same $\mathrm{R}_{\mathrm{G}}^{2}$ versus $\mathrm{R}_{\mathrm{G}}^{2} \mathrm{q}^{2}$ for these cases. 


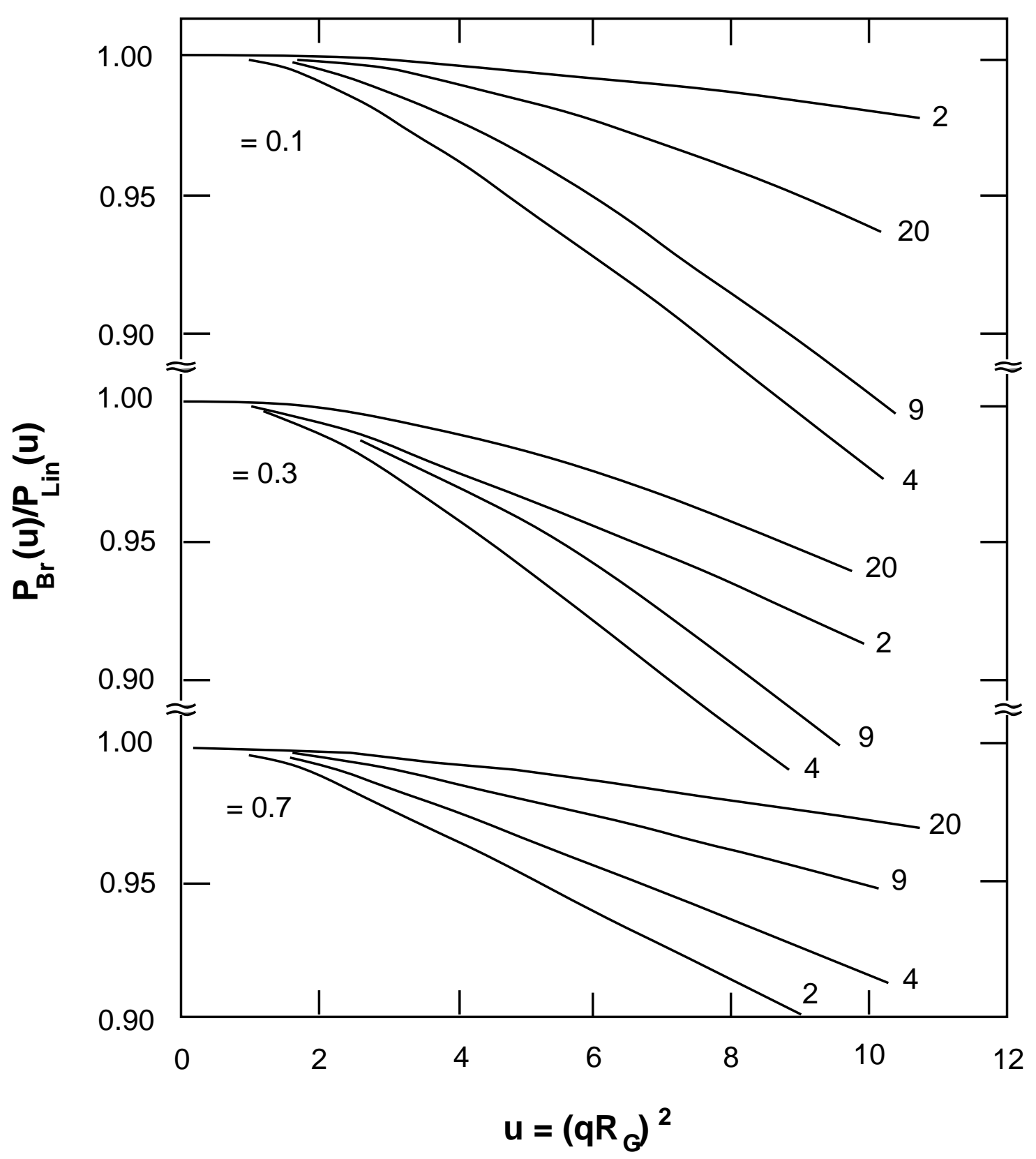

Figure 2 Examples of $\mathrm{P}(\mathrm{q})$ for comb-shaped branched chain polymers divided by $\mathrm{P}(\mathrm{q})$ for linear chains with the same $\mathrm{R}_{\mathrm{G}}^{2}$. The number of branches is indicated, along with the fraction $\varphi$ of mass in the backbone of the branched chain, see reference [6]. 


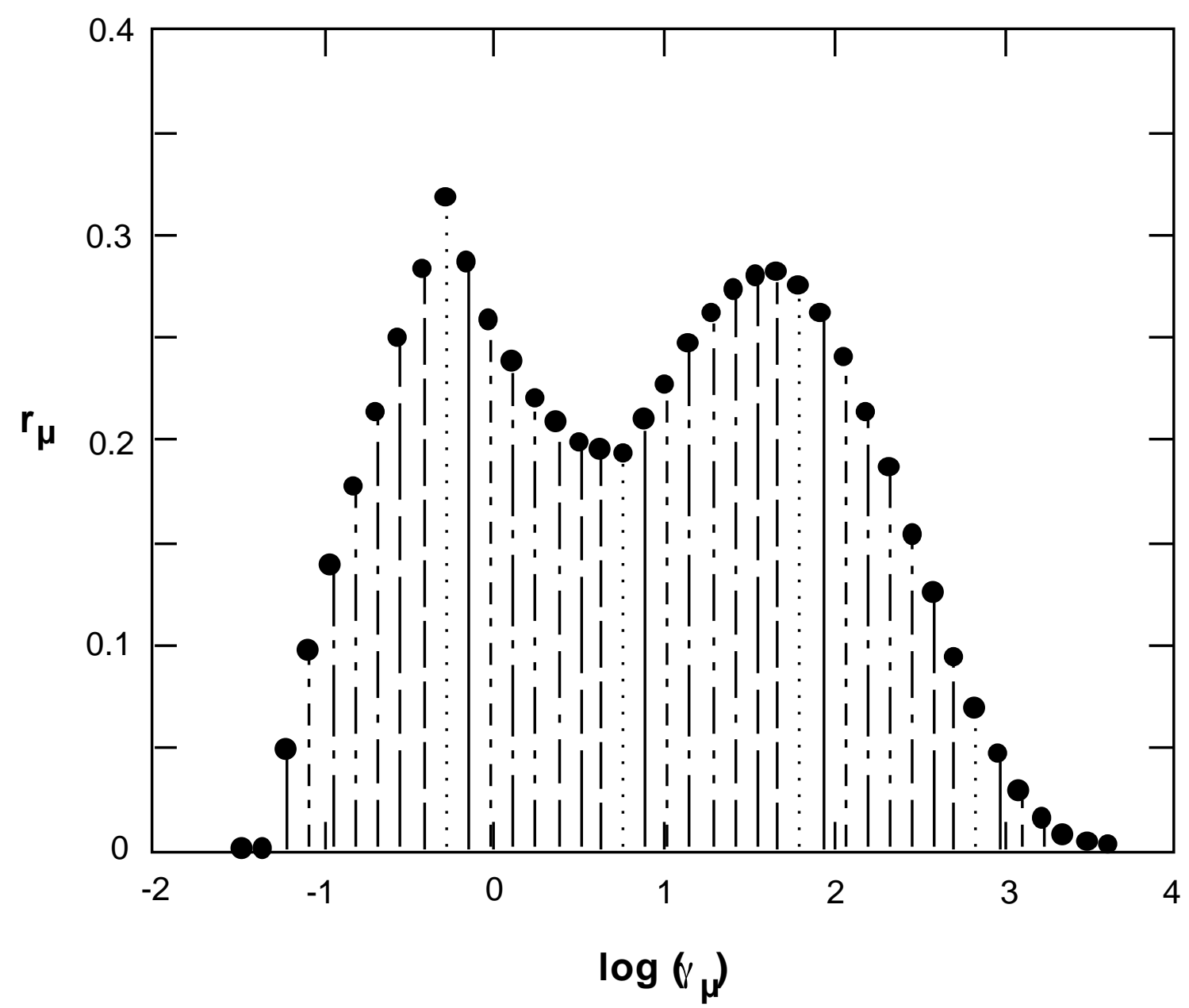

Figure 3 An example of the results of an inverse Laplace transform method to data on $\mathrm{g}^{(2)}(\tau ; q, \mathrm{c})$ exhibiting a nonexponential behavior. As discussed in the text, eight sets of analyses, each with five terms, but different shortest relaxation rates were applied. The sets are distinguished by the differing lines (solid, dashed, etc.). The data are from reference [27]. 


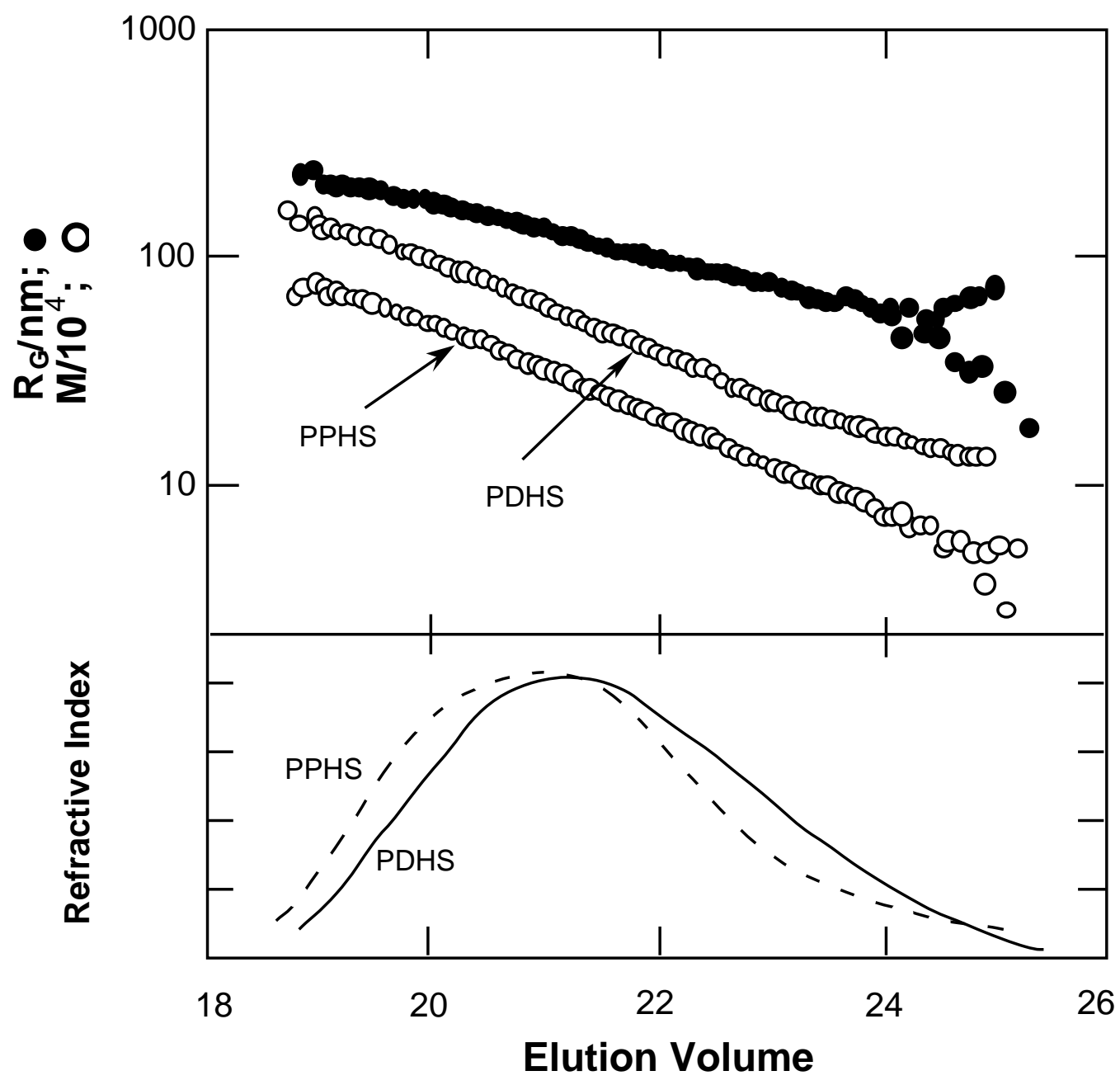

Figure 4 An example of the use of multi-angle light scattering as an SEC detector in the analysis of poly(di- $n$-hexylsilane), PDHS, and poly(phenyl- $n$-hexylsilane), PPHS. The upper panel gives $\mathrm{M}_{\mathrm{e}}$ and $\left(\mathrm{R}_{\mathrm{G}}^{2}\right)_{\mathrm{e}}$ resulting from analysis of the multi-angle scattering data, and the lower panel gives the response from the differential refractive index, normalized to give the same peak response. The data are from reference [29]. 


\section{Table Titles}

Table 1 Advantages/Disadvantages of Light Scattering

Table 2 Light Scattering Average Mean-Square Radius of Gyration and Hydrodynamic Radius 


\section{Figure Captions}

Figure 1 Examples of $\mathrm{P}(\mathrm{q})^{-1}$ versus $\mathrm{R}_{\mathrm{G}}^{2} \mathrm{q}^{2}$ for random-flight linear chains $(\mathrm{C})$, rodlike chains (R), disks (D) and spheres (S); expressions for $\mathrm{P}(\mathrm{q})$ for these cases are given in the Appendix. The insert shows the ratio of the logarithm of $P(q)$ divided by $P(q)$ for the coil with the same $R_{G}^{2}$ versus $R_{G}^{2} q^{2}$ for these cases.

Figure 2 Examples of $\mathrm{P}(\mathrm{q})$ for comb-shaped branched chain polymers divided by $\mathrm{P}(\mathrm{q})$ for linear chains with the same $\mathrm{R}_{\mathrm{G}}^{2}$. The number of branches is indicated, along with the fraction $\varphi$ of mass in the backbone of the branched chain, see reference [6].

Figure 3 An example of the results of an inverse Laplace transform method to data on $\mathrm{g}^{(2)}(\tau ; q, \mathrm{c})$ exhibiting a nonexponential behavior. As discussed in the text, eight sets of analyses, each with five terms, but different shortest relaxation rates were applied. The sets are distinguished by the differing lines (solid, dashed, etc.). The data are from reference [27].

Figure 4 An example of the use of multi-angle light scattering as an SEC detector in the analysis of poly(di- $n$-hexylsilane), PDHS, and poly(phenyl- $n--$ hexylsilane), PPHS. The upper panel gives $\mathrm{M}_{e}$ and $\left(\mathrm{R}_{\mathrm{G}}^{2}\right)_{e}$ resulting from analysis of the multi-angle scattering data, and the lower panel gives the response from the differential refractive index, normalized to give the same peak response. The data are from reference [29]. 